Review Article

\title{
Neurodevelopmental Disorders and Environmental Toxicants: Epigenetics as an Underlying Mechanism
}

\author{
Nguyen Quoc Vuong Tran and Kunio Miyake \\ Department of Health Sciences, Graduate School of Interdisciplinary Research, University of Yamanashi, 1110, Shimokato, Chuo, \\ Yamanashi 409-3898, Japan \\ Correspondence should be addressed to Kunio Miyake; kmiyake@yamanashi.ac.jp
}

Received 21 February 2017; Accepted 2 April 2017; Published 8 May 2017

Academic Editor: Saivageethi Nuthikattu

Copyright (c) 2017 Nguyen Quoc Vuong Tran and Kunio Miyake This is an open access article distributed under the Creative Commons Attribution License, which permits unrestricted use, distribution, and reproduction in any medium, provided the original work is properly cited.

\begin{abstract}
The increasing prevalence of neurodevelopmental disorders, especially autism spectrum disorders (ASD) and attention deficit hyperactivity disorder (ADHD), calls for more research into the identification of etiologic and risk factors. The Developmental Origin of Health and Disease (DOHaD) hypothesizes that the environment during fetal and childhood development affects the risk for many chronic diseases in later stages of life, including neurodevelopmental disorders. Epigenetics, a term describing mechanisms that cause changes in the chromosome state without affecting DNA sequences, is suggested to be the underlying mechanism, according to the $\mathrm{DOHaD}$ hypothesis. Moreover, many neurodevelopmental disorders are also related to epigenetic abnormalities. Experimental and epidemiological studies suggest that exposure to prenatal environmental toxicants is associated with neurodevelopmental disorders. In addition, there is also evidence that environmental toxicants can result in epigenetic alterations, notably DNA methylation. In this review, we first focus on the relationship between neurodevelopmental disorders and environmental toxicants, in particular maternal smoking, plastic-derived chemicals (bisphenol A and phthalates), persistent organic pollutants, and heavy metals. We then review studies showing the epigenetic effects of those environmental factors in humans that may affect normal neurodevelopment.
\end{abstract}

\section{Introduction}

Neurodevelopmental disorders are a group of conditions characterized by impairments of social skills or intelligence with onset in the developmental period. According to the Diagnostic and Statistical Manual of Mental Disorders, Fifth Edition (DSM-V), they include intellectual disability (Intellectual Developmental Disorder), communication disorders, autism spectrum disorder (ASD), attention deficit hyperactivity disorder (ADHD), specific learning disorders, and motor disorders [1]. In 2011-2013, the estimated prevalence for ASD and other neurodevelopmental disabilities in children aged 3 to 17 years in the United States were 2.24\% (1 in 45 ) and $3.57 \%$ ( 1 in 28), respectively [2]. Alarmingly, The Autism and Developmental Disabilities Monitoring (ADDM) Network that surveils children aged 8 years showed that the prevalence of ASD has increased from $0.66 \%$ to $1.46 \%$ over 10 years from 2002 to $2012[3,4]$. Similarly, the prevalence of ADHD in children from 3 to 17 years also showed a $25.64 \%$ increase from $7.8 \%$ to $9.8 \%$ from 2003 to $2015[5,6]$. The reasons for the increasing trend in ASD and ADHD are still controversial; explanations include changes in diagnostic criteria, reporting methods, or other factors such as environment, culture, and social-economic status that may affect the prevalence of neurodevelopmental disorders [7-9]. A previous study found indeed that the changes in diagnostic criteria alone account for only $33 \%$, and a combination of changes in diagnostic criteria and reporting methods account for $60 \%$ of the increase in prevalence of ASD [7]. The search for etiologic and risk factors of neurodevelopmental disorders remains therefore an urgent issue and calls for further monitoring and research.

In the 1980s, epidemiologic studies by Barker et al. in England and Wales found that areas with high ischemic heart disease mortality rates also had high infant mortality rates at the time when the observed generation was in its early 
childhood. A birth cohort study from 1911 by the same group found that the lower the birth weight, the higher the cardiovascular disease mortality rate, hypertension, and impaired glucose tolerance rate [10-13]. From these findings, Barker et al. proposed an "adult-onset of fetal origin" hypothesis called "Barker's hypothesis," stating that a low nutritional environment in the fetal stage increases the risk of chronic diseases in adulthood, which is the concept underlying the Developmental Origin of Health and Disease (DOHaD) [14]. The DOHaD concept is that the fetal-childhood environment affects the risk of chronic diseases in adulthood, based on knowledge obtained from epidemiological assessments of birth cohort studies. Research on developmental biology and human and animal physiology showed that the environment of fetal and early childhood have strong effects on development, health maintenance, and incidents of disease [15]. Based on the DOHaD theory, obesity, diabetes, and mental illness tend to develop in children born from women who are exposed to starvation during wartime [16-18]. Furthermore, folate and vitamin deficiency in the mother during pregnancy increases the risk of neurodevelopmental disorder [19-21]. In addition to maternal malnutrition, maternal stress due to various reasons is associated with child behavioral problems including ASD and ADHD [22-25].

Not limited to maternal stress or malnutrition, epidemiological studies have linked maternal exposure to environmental toxicants and neurodevelopmental disorders, particularly ASD and ADHD $[26,27]$. Here, we focus on reviewing the relationship between maternal exposure to environmental toxicants and neurodevelopmental disorders and propose epigenetics as the linking mechanism.

\section{Epigenetics and Neurodevelopmental Disorders}

Epigenetics is defined as "a stably heritable phenotype resulting from changes in a chromosome without alterations in the DNA sequence" [28]. Thus, epigenetic mechanisms rely on DNA methylation, histone modification, histone variation, or noncoding RNAs, which change the chromatin structure and consequently control gene expression. Many conditions that fall under the term "neurodevelopmental disorders" are related to epigenetic abnormalities, namely the Prader-Willi syndrome, Angelman syndrome, ICF syndrome, and Rett syndrome.

Genomic imprinting is the concept underlying epigenetics, introduced 20 years ago. Specifically, in genomic imprinting, only one allele of a gene is expressed, depending on its parental origin. To date, more than 70 imprinted genes are identified in the human genome, together with a number of related diseases named "imprinting disorders" [29]. The Prader-Willi syndrome and Angelman syndrome are two illustrative examples for imprinting disorders originating in the 15q11-13 imprinted region. In this region, normally, the paternally derived chromosome expresses several genes such as small nuclear ribonucleoprotein polypeptide $\mathrm{N}$ $(S N R P N), S N R P N$ upstream reading frame (SNURF), small nucleolar RNA, C/D box 116 cluster (SNORD116), and melanoma-associated antigen (MAGE) family L2 (MAGEL2), while ubiquitin protein ligase E3A $(U B E 3 A)$ is expressed from the maternally derived chromosome specifically in neurons. The Prader-Willi syndrome, a neurodevelopmental disorder characterized by a short stature, muscle tension reduction, overeating and subsequent obesity, diabetes, and personality persistence, is caused by mutation or deletion of the paternally derived chromosome or by a maternal uniparental disomy (both chromosomes 15 were derived from the mother) [30]. The Angelman syndrome, characterized by intractable epilepsy and severe developmental delay, is caused by a genomic imprinting abnormality of the 15q11q13 region, similar to the Prader-Willi syndrome, but its pattern is reversed. The causative gene is the UBE3A gene, expressed on the maternal chromosome but not the paternal chromosome in neurons [31]. In addition to the loss of gene expression in the 15q11-13 region, which results in the Prader-Willi syndrome or Angelman syndrome according to the parental origin of the chromosome, overexpression of genes in this locus results in a different disorder: the 15q11-13 duplication syndrome (Dup15q). The duplication is almost always of maternal origin and the disease is characterized by hypotonia, speech disorder, behavior disorders, abnormal EEG, and developmental delay with other associated symptoms such as autism and seizures [32]. Very recently, a large whole-genome bisulfite sequencing (WGBS) analysis on human brain and neuronal cell culture model of Dup15q revealed a global decrease in DNA methylation in both CpG regions and long intersperse element 1 (LINE-1) repetitive elements [33]. Furthermore, when compared to control samples, gene ontology analyses in the same study found that the differentially methylated regions are enriched for genes related to cell adhesion, brain, calcium channel, and membrane, many of which are known to have functions at neuronal synapses and are related to ASD [33]. More importantly, the authors also observed overlapped changes in DNA methylation and gene expression between neuronal cells exposed to polychlorinated biphenyl (PCB 95), an environmental toxicant, Dup15 model cells, and Dup15q model cells exposed to PCB 95, demonstrating an effect of environmental toxicant on neuronal genes via epigenetic mechanism, which will be discussed later in this review. Together with previous studies performed on postmortem human brain tissue, the results have suggested that epigenetic alterations, together with genetic dosage, contributed to the changes in gene expression in the pathology of the disease $[34,35]$. The fact that loss or enhanced function of these imprinted genes leads to developmental disorders implies the importance of proper gene expression in neurodevelopment.

Another congenital disease caused by epigenetic abnormalities that impact development is ICF syndrome. The name ICF stems from the main symptoms of the disease: immunodeficiency, instability of the chromosome resulted from centromere instability, and facial anomalies. In this disease, the heterochromatin region near the centromere of chromosomes 1,9 , and 16 , which is normally strongly methylated, is hypomethylated by DNA methyltransferase (DNMT3B) deficiency, resulting in chromosome instability [36]. DNMT3B, together with DNMT3A, are considered 
de novo DNA methyltransferase, acting to add methyl group to the cytosine residues in DNA. In vitro knockout or knockdown of DMNT3B was resulted in hypomethylation of satellite 2 repeats, leading to centromeric instabilities [37, 38]. Using induced pluripotent stem cells (iPSCs) and WGBS, a previous study revealed the alteration of gene expression and hypomethylation of promoters and enhancers in genes related to ICF syndrome phenotypes [39]. Another study revealed that changes in gene expression during neuronal differentiation were similar between DNMT3B knockdown human embryonic stem cells (hESCs) and ICF patientderived iPSCs and that DNMT3B knockdown caused hypomethylation at pericentromeric regions and $\mathrm{X}$ chromosome but not at promoter regions of divergent genes as analyzed by WGBS [38]. Of late, there are studies that signified the role of DNMT3B in the maintenance of intragenic CpG methylation to ensure proper mRNA transcription and regulate alternating splicing $[40,41]$. Moreover, a disease caused by a genetic mutation of DNMT3A was reported, characterized by overgrowth and developmental disorders [42]. These findings suggest that DNA methylation enzymes have important functions in the development of the immune system and the cranial nervous system.

Rett syndrome (RTT), a disease characterized by repeated hand movements, epileptic seizures, staggering gait, and autistic tendencies, is a representative case of a developmental disorder caused by epigenetic abnormalities. Most of the cases of typical RTT are caused by a mutation in methyl CpG-binding protein 2 (MeCP2) located on Xq28 [43]. Thus, RTT is a dominant inherited X-linked disease that affects $1: 10,000$ female live births, while affected males become embryonic lethal. In the brain, MeCP2 is highly expressed and increases over time during development. It is not only abundant in neurons but also expressed in astrocyte and glia cells, which is suggested to play an important role in the pathology of RTT. MeCP2 was first described as binding to methylated cytosine, recruiting other proteins such as nuclear receptor corepressor (NCOR)-SMRT (a silencing mediator of retinoic acid and thyroid hormone receptors) and corepressor complex Sin3A/HDACs to form a repressor complex and suppress gene expression. In addition to its repressing function, our knowledge of $\mathrm{MeCP} 2$ has increased overtime, and it is now known that $\mathrm{MeCP} 2$ can interact with coactivator cyclic AMP-responsive element-binding protein 1 (CREB1) to activate the expression of its target genes, alternate splicing sites via an interaction with YB1, a Y-box transcription factor, or regulate microRNA (miRNA) processing by interacting with DGCR8 to prevent the formation of the Drosha-DGCR8 complex [44]. Specifically, among various brain cells, it regulates the expression of a number of genes involved in synaptic functions or brain development-brainderived neurotrophic factor $(B D N F)$, distal-less homeobox 5 (DLX5), inhibitor of differentiation (ID), corticotropinreleasing hormone $(C R H)$, insulin-like growth factor binding protein 3 (IGFBP3), cyclin-dependent kinase like 1 (CDKL1), protocadherin beta 1 ( $P C D H B 1)$, and protocadherin 7 (PCDH7) [45] — and regulates glutamatergic synapse formation in early postnatal development [46]. In recent years, using RTT patient-derived iPSCs, several studies have revealed the defects of MeCP2 mutant neurons as seen in mouse models-smaller soma size, reduction of the number of synapse and spine, altered calcium signaling, and electrophysiological defects $[47,48]$ - or proposed a role of astrocytes in RTT $[49,50]$. On the other hand, not only the loss of normal $\mathrm{MeCP} 2$ function but also a gain in MeCP2 function was found to cause neurodevelopmental disorders [51, 52]. MeCP2 transgene mouse models recapitulated the phenotype of the $\mathrm{MeCP} 2$ duplication syndrome, showing an increase in anxiety and deficits in coordination, learning, and memory [53].

Taken together, epigenetic mechanisms play an important role in brain development, especially the methylation of DNA. Any disturbances in the establishment, maintenance, or reading of DNA methylation are associated with neurodevelopmental disorders. As mentioned above, maternal stress, malnutrition, and exposure to environmental toxicants could alter the normal development and are related to neurodevelopmental disorders. Moreover, it has been long thought that epigenetics is one of the underlying mechanisms of the $\mathrm{DOHaD}$ hypothesis [54], and epigenetic patterns are more susceptible to environmental stresses than genome sequences [55]. There is evidence that expose to various environmental factors, such as mental stress and malnutrition during fetal and neonatal periods which can induce alterations in the epigenomics of the offspring [56-61]. Therefore, epigenetic mechanisms, particularly DNA methylation, may be the link between environmental toxicants and neurodevelopmental disorders.

\section{Environmental Toxicant Exposure and Neurodevelopmental Disorders}

\subsection{Experimental Evidence of Environmental Toxicant Effects on Neurodevelopment}

3.1.1. Maternal Smoking. Maternal smoking during pregnancy has been related to many adverse effects in offspring including decreased birth weight, congenital anomalies, smaller neonate head circumferences, and sudden infant death syndrome [62]. The prevalence of woman smoking at any time during pregnancy differs between countries, ranging from $5 \%$ to $19 \%$, and about one fifth of these quit smoking in later stages of the pregnancy $[63,64]$. Tobacco smoke contains thousands of compounds that may have neurotoxic effects; among those, nicotine is the one most widely investigated. Prenatal exposure to nicotine has been proven to cause abnormal cognitive and emotional behavior and attention deficits [65-67]. Studies with the purpose to find out the mechanism of the relationship between smoking and behavioral problems exist, but there is no agreement. In brief, rat models treated with nicotine and mimicking a coexisting intermittent hypoxia state showed that nicotine-induced hypoxia reduces the expression of cyclin-dependent kinase 5 (Cdk5), an indispensable gene in the central nervous system, and plays a critical role in neurodevelopment [68] and delayed neuronal migration [69]. Another study has shown that prenatal nicotine exposure only impairs neurogenesis but not neuronal migration as observed by reducing the number of glutamatergic neurons in the medial prefrontal 
cortex and decreasing and disrupting cell cycles of neural progenitor cells in the ventricular and subventricular zones [70]. Recently, using tobacco smoke extract (TSE) to better demonstrate the effects of tobacco smoke, studies have suggested that TSE may have different effects on neurodifferentiation compared to nicotine alone [71]. Using PC12 cells in a neural differentiation model, a study showed that TSE exerted higher effect on inhibiting DNA synthesis and reducing cell proliferation compared to equivalent concentration of nicotine alone in undifferentiated cells, while in differentiated cells, TSE promoted the growth of dopaminergic phenotypes [72].

3.1.2. Plastic-Derived Chemicals: Bisphenol A and Phthalates. Bisphenol A (BPA) is a chemical predominantly polymerized or modified and used in the plastic industry; thus, it is used in a wide range of consumer goods and commodities, especially in daily used food and beverage containers, dispensers, baby bottles, microwave cookware [73], or in healthcare-related products such as medical devices [74] or dental composite resins [75]. However, incomplete reaction or degradation of the polymer may release residual monomers of BPA. Human exposure to BPA is widespread, Centers for Disease Control and Prevention (CDC) reported BPA found in the urine of more than $90 \%$ of the US population, and more importantly, the concentration is higher in children (available in https:// www.cdc.gov/exposurereport/). BPA has been proven to disrupt the endocrine system by interacting with estrogen, androgen, or thyroid hormone receptors [76, 77] and its effects on the reproductive system have been widely investigated [78]. In addition, perinatal exposure to BPA reduces synaptogenesis and synaptic proteins, alters the structure of synapse, affects behavior, and impairs learning-memory in male mice $[79,80]$. Neonatal and perinatal BPA exposure affects postnatal gene expression and morphology of sexually dimorphic regions in the rat hypothalamus $[81,82]$. In addition to effects on neurons, in the prefrontal cortex of the rat, adolescent exposure to BPA decreases the number of microglia in male rats and increases the number of microglia in female rat in adulthood, but does not affect the number of neurons or astrocytes, suggesting a long-term sex- and cell type-dependent effect of BPA [83].

Together with BPA, phthalates, chemicals used in the plastic industry, are also known to disrupt the endocrine system [84]. Based on their molecular weight and chemical properties, phthalates are classified into 2 subtypes that have different usage. High molecular weight phthalates including di-2-ethylhexyl phthalate (DEHP), butylbenzyl phthalate $(\mathrm{BBz}), \operatorname{di}($ n-octyl) phthalate (DOP), diisononyl phthalate (DiNP), and diisodecyl phthalate (DiDP) are used in food containers, flooring, and wall covering and in medical tubing. Low molecular weight phthalates, dimethyl phthalate (DMP), diethyl phthalate (DEP), and dibutyl phthalate (DBP) are used in personal care products [84] or the coating of some medications [85]. Moreover, an earlier study has shown that BPA and phthalates may leak from food containers and enter the human body, as the usage of food that is not canned or packaged in plastic reduces urine levels of BPA and phthalates significantly [86]. While BPA and phthalate exposure is widespread, more importantly, phthalates have been proven to pass to the baby through the placenta and breast milk $[87,88]$. An earlier study has claimed that DEHP added to the diet of mice has negative effects on behavioral tests of the offspring, although the author discussed that the results in some tests may not be the consequence of DEHP. Furthermore, the author debated that the concentration of DEHP in the environment may not be the cause for adverse effects in humans [89]. It is however known that DEHP is metabolized into mono-2-ethylhexyl phthalate (MEHP), and the effects of MEHP may therefore represent the toxic effects of DEHP. In a differentiation model of PC12 cells using nerve growth factor (NGF), MEHP exposure for 4 days enhanced neurite outgrowth induced by NGF [90]. MEHP upregulated choline acetyl transferase (ChAT) mRNA, a marker for cholinergic neurons, while it downregulated tyrosine hydroxylase (TH), a marker for dopaminergic neurons, suggesting that exposure to MEHP affects neuron differentiation [90]. This result suggests an effect of phthalates, particularly MEHP, on midbrain dopaminergic neurons, which are implicated in ADHD or schizophrenia (reviewed in [91]). In the developing rat brain, maternal exposure to DEHP decreases the concentration of essential lipids, particularly free cholesterol and sphingomyelin, as well as the mono- and poly-unsaturated fatty acid lipid composition, which plays an important role in neurodevelopment [92]. In respect to low molecular weight phthalates, prenatal and postnatal DBP exposure upregulates aromatase, an enzyme that has an important role in reproduction and neuroprotection, and downregulates estrogen receptor beta $(\mathrm{ER} \beta)$, which in turn reduces the expression of phosphate CREB and BDNF, two important neuroprotective proteins, in the rat hippocampus [93]. In line with these results, recently, in mouse neocortical neuronal cultures, treatment with DBP has been shown to impair the estrogen receptor pathway and induce neurotoxicity in a mechanism involved in the aryl hydrocarbon pathway [94].

3.1.3. Persistent Organic Pollutants (POPs). Persistent organic pollutants (POPs) have two main characteristics: resistance to environment degradation and accumulation in human or animal tissue. POPs are comprised of many different structures that have different toxicity [95]. Polychlorinated biphenyls (PCBs), a group of 209 related structures of chlorinate substituents on biphenyl rings, are used for heat resistance; organochloride pesticides (OCPs), such as hexachlorobenzene (HCB) or dichlorodiphenyltrichloroethane (DDT), are examples of POPs, many of them well-known as endocrine disruptors [96]. Exposure to POPs is widespread through environmental pollutants, daily used cosmetics, daily used items, or food. Importantly, POPs can be transferred from the mother to the child prenatally through the placenta [97] or postnatally by secreting into breast milk [98]. Therefore, prenatal and postnatal exposure to POPs may have many adverse health effects on the immune system and the reproductive system and may be related to other diseases such as cancer, diabetes, and obesity or to adverse pregnancy outcomes [98]. Moreover, since it is well-known that thyroid hormones are essential for neurodevelopment, prenatal and 
postnatal exposure to POPs could lead to neurobehavioral problems in children [99]. PCBs and OCPs have been suggested to be related to the pathogenesis of many neurodevelopmental and neurodegenerative disorders (reviewed in [100]). Experiments in rats exposed to PCBs during gestation and lactation showed increased activity of caspase 3 and DNA fragmentation, a marker for apoptosis, compared to control at postnatal day 1 but not at postnatal day 21 [101], suggesting that PCBs induce apoptosis in the developing brain. Another study in mice showed that low doses of non-dioxin-like polychlorinated biphenyls (NDL PCBs) given to the mother during the lactation period altered behavioral performances recorded during the mice's development [102]. Moreover, neurobehavioral toxicity of NDL PCBs increased from postnatal day 9 to postnatal day 28, but disappeared with increasing age, except for its effect on anxiety-related behavior, which was sex-dependent and permanent [102]. Newer chemicals that belong to POPs such as perfluoroalkyl acid (PFAA), perfluorooctanoic acid (PFOA), or perfluorooctane sulfonate (PFOS) were also shown to have neurotoxicity in mice or neuronal cell cultures by inducing apoptosis, inducing oxidative stress, and inhibiting neuronal differentiation [103-105], all of which may contribute to the changes in spontaneous behavior, habituation, and learning and memory observed in mice [106]. Exposure to PFOS and PFOA has also been shown to repress the expression of glutamine synthase-related genes and increase the extracellular level of glutamate in mouse primary astrocytes [105].

3.1.4. Heavy Metals. Methyl mercury (MeHg) and lead are two representative heavy metals that have negative effects on neurodevelopment. Humans are widely exposed to $\mathrm{MeHg}$ through the consumption of contaminated seafood. The neurotoxicity of $\mathrm{MeHg}$ has been recognized since the incidence of Minamata bay, coining the term "Minamata disease." The Minamata disease has occurred in humans who ingested fish and shellfish contaminated by $\mathrm{MeHg}$ discharged in waste water from a chemical plant. Children of women who had no symptoms of $\mathrm{MeHg}$ poisoning also showed abnormalities or neurodevelopmental problems [107]. Animal models have shown that gestational and lactational exposure to $\mathrm{MeHg}$ can cause significant deficits in behavioral tests and learning disabilities [108, 109], although a recent study showed that exposure to low doses of $\mathrm{MeHg}$ only affects the preadolescent but not the young adult period [110]. Experimental studies in animal or cell lines suggested that $\mathrm{MeHg}$ induced neurotoxicity by inducing oxidative stress, altering the kynurenine pathway and NMDA receptors, and impairing cytoskeleton instabilities [111-114]. Exposure to lead is also widespread as the sources may be air or water, and even a low level exposure to lead may cause negative effects in humans [115]. Prenatal and lactational lead exposure has been proven to affect learning and memory in mice by inducing pathological changes in the ultrastructure of synapses, downregulating synaptic genes, insulin-degrading enzyme (IDE) and insulin-like growth factor 2 (IGF2), and increasing beta amyloid 40 (A $\beta 40)$ and tumor necrosis factor- (TNF-) $\alpha$ [116$119]$. Together with studies in mice, a study on human neurons revealed that exposure to lead increases the expression of serine/threonine protein phosphatases, which are associated with learning and memory [120].

Taken together, experimental studies indicate negative effects of environmental toxicants on neuronal cells and/or neurodevelopment; the mechanisms are however not fully understood, and certain findings are still controversial. Although some results are not directly related to any disease, the findings presented here support the hypothesis of $\mathrm{DOHaD}$ on neurodevelopmental disorders. For a complete evaluation of the $\mathrm{DOHaD}$ hypothesis in respect to neurodevelopmental disorders, cohort studies in human populations also have to be considered. Due to the large number of epidemiological studies on environmental toxicants, we only focus on several recent birth cohort studies that focused on those environmental toxicants described above.

\subsection{Epidemiological Evidence for the Relationship between Environmental Toxicants and Neurodevelopmental Disorders}

3.2.1. Maternal Smoking. Several earlier reviews of studies from 1975 showed a relationship between tobacco smoke exposure and poorer academic achievement as well as an increased risk of mental retardation and neuropsychological and behavior problems; there were however still inconsistencies [121, 122]. Many studies observed a higher risk for ASD or ADHD symptoms in subjects prenatally exposed to environmental tobacco smoke (ETS) and have been reviewed elsewhere [63, 123-128]. Recently, several cohort studies in different countries supported the link between ADHD and prenatal tobacco exposure [129-131]. A mother-child cohort study of 1113 families in France that followed the child up to 5 years of age showed that maternal smoking predicted high symptoms of hyperactivity or inattention [129]. A Danish cohort study with a 7-year follow-up reported that not only maternal smoking but also the use of nicotine replacement products by the mother increased the risk for ADHD [131]. A Finish cohort study with more than 50,000 participants showed that, after adjusting for confounding factors, maternal smoking, no matter whether only in the first trimester or continuing after the first trimester, is associated with an increased risk for ADHD [130]. In another study that followed the child up to 15 years of age showed that maternal smoking of more than 10 cigarettes/day increased the risk for Tourette syndrome, Tourette syndrome comorbid with $\mathrm{ADHD}$, and chronic tic disorders [132]. On the other hand, a case-cohort study of 633,989 children from parts of 11 US states and a recent meta-analysis of 6 cohort and 9 casecontrol studies found no relationship between ASD and ETS $[133,134]$.

3.2.2. BPA and Phthalates. The relationship between plasticderived chemicals and neurodevelopmental disorders is more complicated because of the sex-dependence of the latter. In a study of 244 mothers and their 3-year-old children, higher gestational BPA concentrations were associated with higher anxiety, hyperactivity, and depression scale scores, especially in girls [135]. However, in several later studies, prenatal BPA exposure was reported to have greater effects on boys [136] or have opposite effects on boys and girls 
[137-139]. Briefly summarized, higher BPA concentrations in the mother's urine samples during pregnancy were associated with higher scores on emotionally reactive, aggressive behavior and inattention symptoms that related to ADHD or conduct disorders. Prenatal phthalate exposure was also shown to be related to behavioral difficulties in children. In a Polish cohort study, prenatal phthalate exposure was inversely correlated with child psychomotor development such as cognitive, language, and motor abilities [140]. In line with this study, a Taiwanese cohort study showed that higher concentrations of DBP and DEHP in maternal urine samples were associated with externalizing disorders in children [141]. In contrast, in a Japanese cohort study, prenatal DEHP exposure did not lead to changes in infant thyroid hormone levels and had no adverse effects on neurodevelopment at early life stage [142].

3.2.3. POPs. The relationship between POPs and neurodevelopmental disorders is also not clear. Several studies in Danish, Greek, and Faroese populations suggested no relationship between POPs and child neurobehavioral problems but a potential link with a reduction in cognitive abilities [143-145]. A German cohort study of polychlorinated dibenzo-p-dioxins and furans (PCDD/Fs) and PCB exposure suggested an effect of PCDD/Fs and PCB on attention performance in healthy children [146]. Another cohort study in a Japanese population showed that prenatal PFOA exposure had negative effects on the neurodevelopment of female infants at 6 months of age as assessed by Mental and Developmental Indices [147]. However, this study found no association between PFOA and neurodevelopment in infants at 18 months of age or PFOS at both 6 and 18 months of age, suggesting that the effects of POPs may be transient during early infancy.

3.2.4. Heavy Metals. The negative effects of heavy metal on neurodevelopment are well described. A recent metaanalysis showed that increase of arsenic and manganese concentrations was associated with lower IQ, and prenatal exposure to manganese increased the risk of ADHD [148]. Other studies found that postnatal exposure to lead, which is measured by blood lead concentration, is associated with an increased risk for neurodevelopmental disorders and a decrease in cognitive scores [149, 150].

Overall, there is an abundance of cohort studies supporting the idea that exposure to environmental toxicants during pregnancy could result in neurodevelopmental disorders in children (summarized in Table 1). The molecular mechanism underlying the relationship between environment and neurodevelopmental disorders is however not clear. There is evidence suggesting that epigenetic mechanisms may constitute the link between environmental toxicants and disorders.

\section{Epigenetic Alterations by Environmental Toxicants}

4.1. Maternal Smoking. DNA methylation is the most wellknown epigenetic mechanism involved in neurodevelopment [153]; thus, many studies on neurodevelopment focus on alterations of DNA methylation patterns (summarized in Table 2). DNA methylation is the process of adding a methyl group to the $5^{\prime}$ position of cytosine. This process mainly happens in a CG context, especially at regions rich in CG (CpG island), and catalyzed by DNA methyltransferase (DNMT) enzymes. DNMT3A and DNMT3B are known as de novo DNMTs that, in combination with DNMT3L, establish the methylation status. During cell division, DNMT1 and its associated proteins maintain the pattern of methylation (recently reviewed in [154]).

Brain-derived neurotrophic factor $(B D N F)$ gene plays a key role in neurodevelopment, neurogenesis, and synaptic plasticity. BDNF has been linked to a number of neurologic disorders including neurodevelopmental disorders [155-157] and is now a gene of interest to investigate the neurological effects of environmental toxicants. Prenatal exposure to maternal cigarette smoking has been reported to induce a long-term effect on adolescent behavior possibly by inducing hypermethylation at BDNF promoter VI and $5^{\prime}$ untranslated region (UTR) [158].

Moreover, maternal smoking has been shown to alter the expression of genes related to neuropeptide signaling and signal transduction, as well as development, particularly tachykinin 3 (TAC3), left-right determination factor 2 (LEFTY2), heparin-binding EGF-like growth factor $(H B E G F)$, mitochondrial fission factor $(M F F)$, and fibulin 1 (FBLN1), via mechanisms possibly related to genome-wide changes in DNA methylation [159]. A recent study showed that maternal smoking during pregnancy induced hypomethylation at $\mathrm{CpG} 3$ and $\mathrm{CpG} 4$ in total $13 \mathrm{CpG}$ of the placental NR3C1 gene, which has shown associations with newborn behavior [160]. Prenatal smoke exposure is known to result in a persistent effect on DNA methylation levels in adult peripheral blood granulocytes, as measured by repetitive element satellite 2 (Sat2) [161]. Epigenome Wide Association Studies (EWAS) provide a powerful tool for the identification of changes in epigenetics, specifically, in DNA methylation, induced by environmental toxicants [162]. One of the largest EWAS, screening 1062 newborn cord blood samples using Infinium Human Methylation 450 (HM450) platform, has identified hypomethylation of the aryl hydrocarbon receptor repressor (AHRR) and growth factor independent 1 transcription repressor (GFI1) and hypermethylation of cytochrome P450 1A1 (CYP1A1) and myosin IG (MYO1G) that were related to maternal smoking [163]. Later, another study focused on changes in the DNA methylation of the AHRR gene and found that the hypomethylation caused by maternal smoking was different between cord blood mononuclear cells, buccal epithelia, and placenta and that AHRR gene hypomethylation was maintained at 18 months [164]. Interestingly, the authors also reported that DNA methylation levels of monozygotic twins were more similar compared to dizygotic twins, suggesting that genetic variance has influences on the methylation level [164]. Another epigenetic mechanism that has been investigated in respect to neurodevelopment involves microRNA, an important regulator of gene expression that was found to have important roles in normal neuronal function and homeostasis [165]. Maccani et al. demonstrated that 


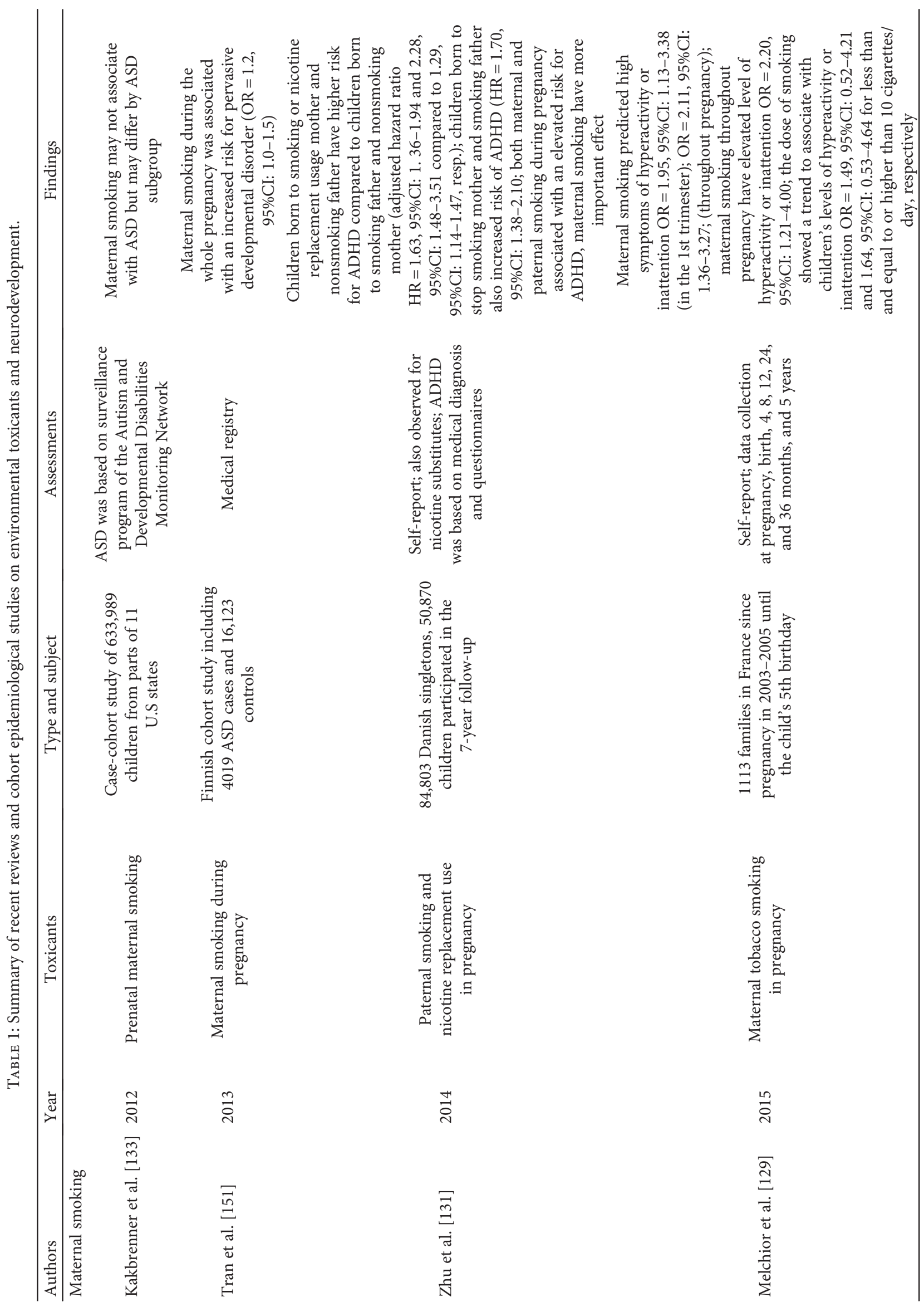




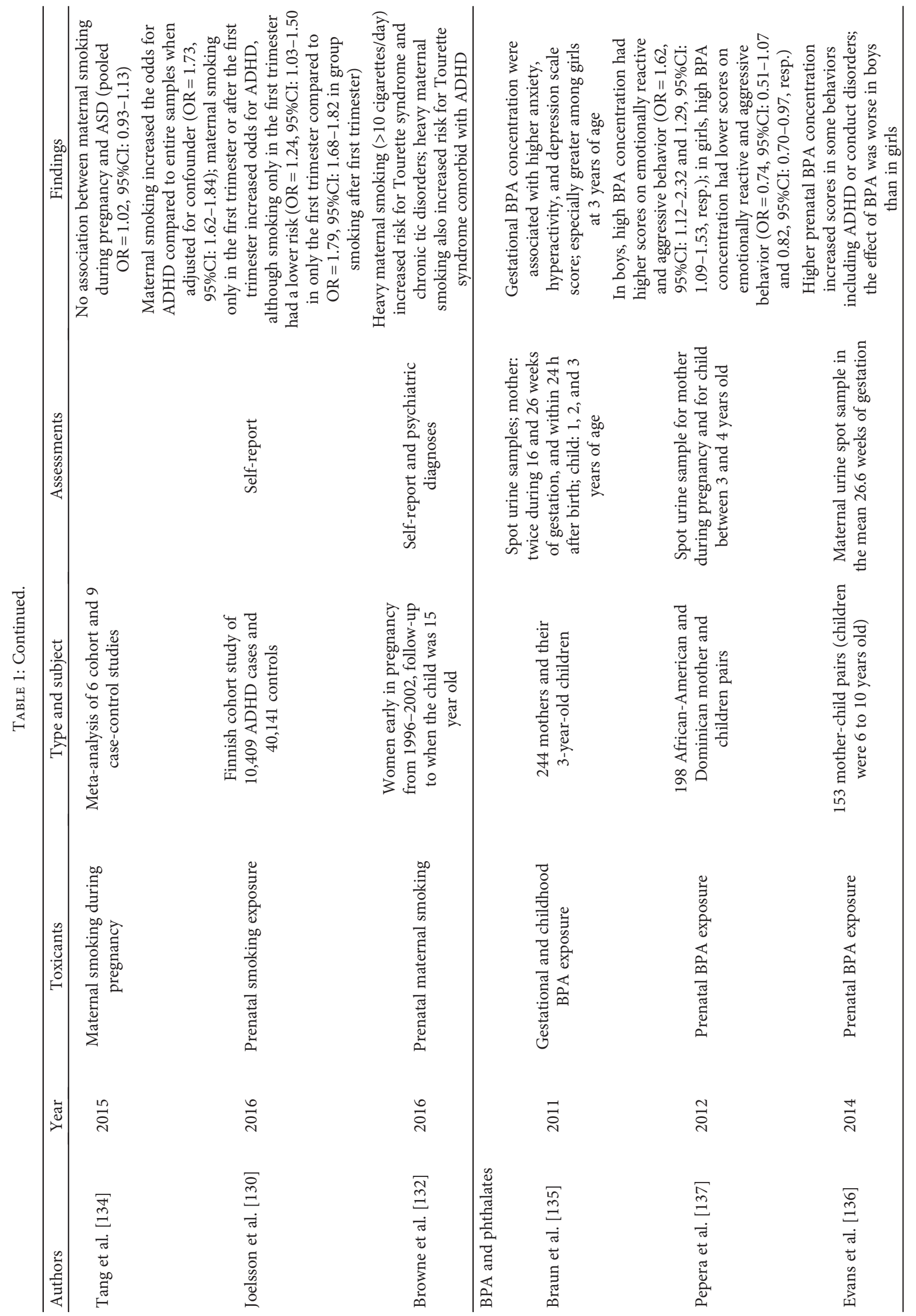




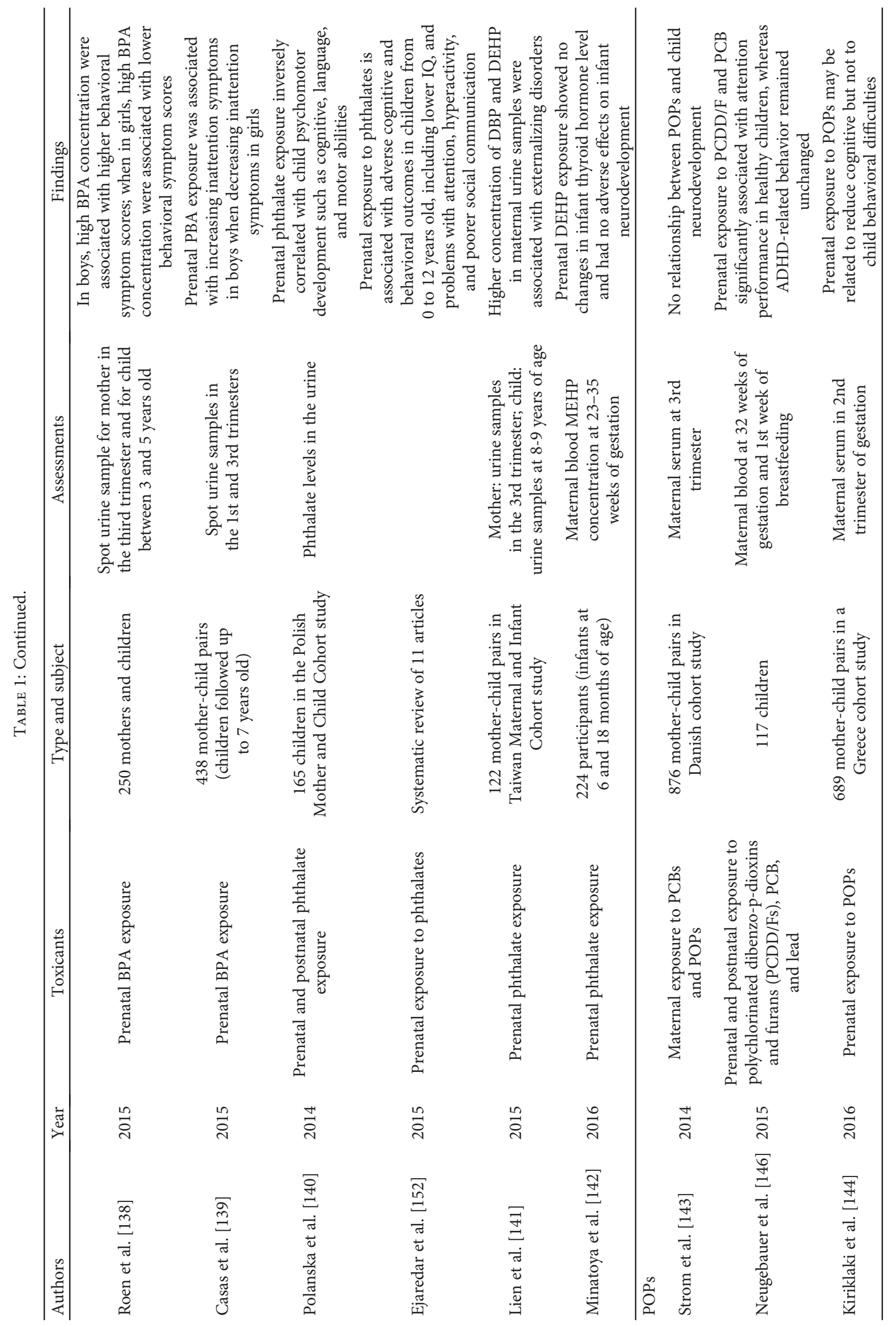









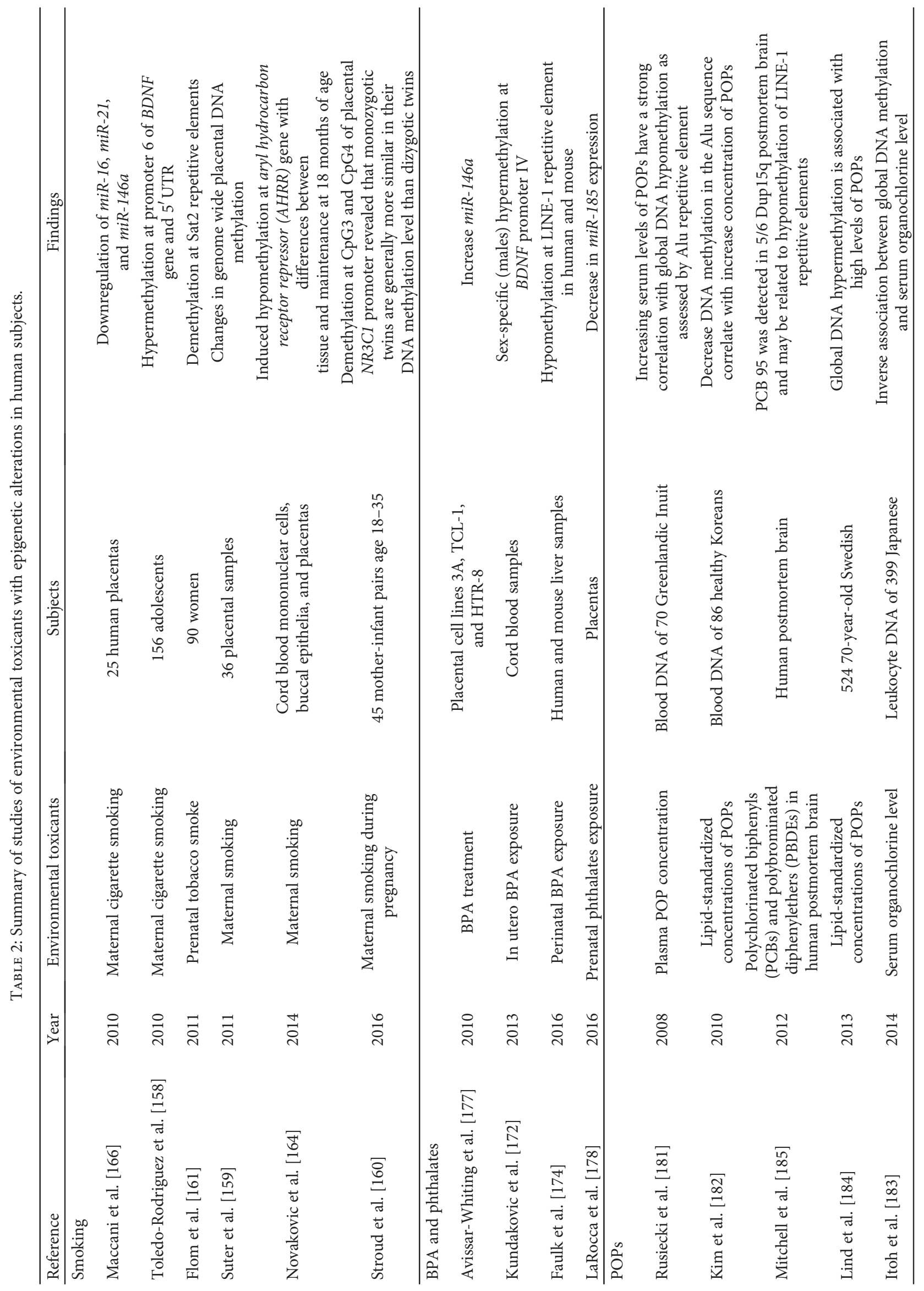




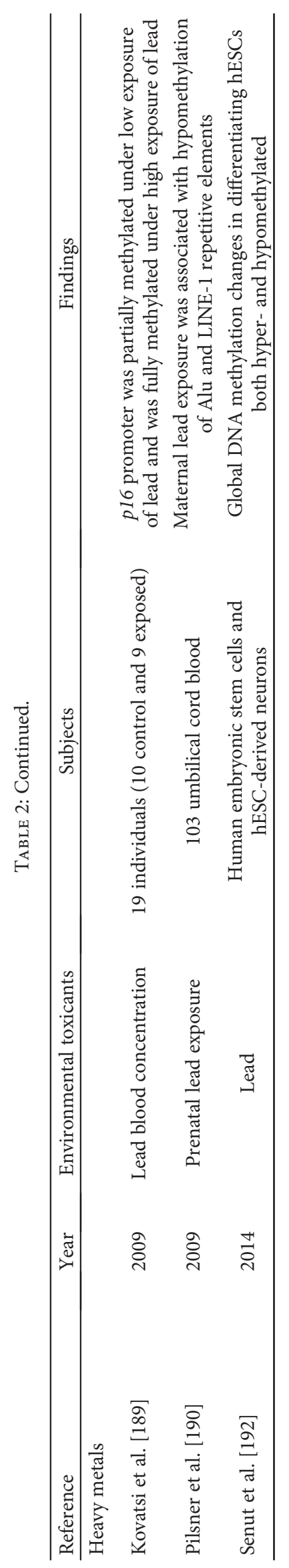


maternal cigarette smoking downregulated miR-16, miR21 , and miR-146a in the placenta, as confirmed in placental cell lines 3A, TCL-1, and HTR8 [166]. Later, the same group showed that high levels of placental miR-146a are associated with increased quality of movement scores; interestingly, high levels of placental miR-16 reduced attention scores in newborns [167]. In addition, smoking, together with other environmental toxicants such as BPA mixture, several POPs, and arsenic, were reported to alter transcription factor binding at promoter regions of miRNAs [168]. The study moreover pointed out that actindependent regulator of chromatin, subfamily a, member 3 (SMARCA3), and Forkhead Box P1 activated in embryonic stem cells (FOXP1_ES) were commonly enriched at promoter regions of miRNAs, suggesting that though different in responsive miRNA, environmental toxicants may have effect on similar transcription factor [168].

4.2. BPA and Phthalates. Most of the knowledge of DNA methylation alteration of BPA and phthalates comes from mouse models. A study on developing fetus mouse brains using spot DNA and methylation-sensitive quantitative PCR techniques showed that exposure to BPA was able to cause both hyper- and hypomethylation [169]. Intrauterine exposure to BPA was also reported to induce hypermethylation at BDNF promoter IV in a sex-specific manner [170]. Prenatal BPA exposure was reported to alter the level of DNMTs in mouse brain and this alteration may be sex-, region-, and dose-dependent. Briefly, gestational BPA exposure decreased DNMT1 but prevented female-specific reduction of DNMT3a in female mouse brains, while leaving the male mouse brain unaffected [171]. In line with this study, another study found that prenatal exposure to BPA decreased DNMT1 and DNMT3a in both the male and female mice prefrontal cortex and hypothalamus, but the alteration happened at different concentrations and at different trends between both sexes [172]. Furthermore, the authors also observed that changes in ER $\alpha$ and DNMTs were related to the changes in DNA methylation of the ER $\alpha$ (Esr 1 ) gene [172], which was also observed in human breast cancer cells after DBP treatment [173]. A recent study reported for the first time that perinatal exposure to BPA induced hypomethylation at LINE-1 repetitive element in the human liver [174]. Given that LINE-1 is suggested to be a risk factor for schizophrenia or autism $[175,176]$, this finding suggests a link between BPA and other neurodevelopmental disorders via alteration of DNA methylation. Placental cell lines treated with BPA show an increase in miR-146a expression compared to untreated cell [177]. High concentration of phthalates in urine was found to be associated with a decrease in the expression of miR-185 in placenta [178]. In rat primary neuron cultures, exposure to BPA increased expression of Mecp 2 and MECP2 binding when reduced histone $\mathrm{H} 3$ lysine 9 acetylation at potassium chloride cotransporter 2 ( Kcc2, Slc12a5) promoter, subsequently, repressed KCC2 expression [179]. It is well known that KCC2 is upregulated during neurodevelopmental period and has important roles in GABAergic function, neuronal plasticity, and formation of dendritic spine (reviewed in [180]).
4.3. POPs. Alterations of DNA methylation due to POPs in humans have been investigated in several studies, although those studies did not directly link to any disorders. The first study on changes in DNA methylation by POPs in a human population was performed using blood DNA of 70 Greenlandic Inuit and found a correlation between increased plasma concentrations of POPs and global DNA hypomethylation [181]. Kim et al. investigated changes in DNA methylation in Alu sequences in healthy Koreans and observed a similar correlation between a decrease in Alu DNA methylation and increased concentrations of POPs [182]. In accordance with these results, a later study by Itoh et al. showed that higher serum concentrations of POPs decreased global DNA methylation in a Japanese population [183]. In contrast, a study by Lind et al. on a population of 70-year-old Swedish found a relationship between high serum levels of POPs and global DNA hypermethylation [184]. Only one study examined PCB levels in human postmortem brains of patients with neurodevelopmental disorders and found that PCBs 95 was detected in 3/6 Prader-Willi syndrome postmortem brains and 5/6 postmortem brains with Dup15q. Moreover, this study reported hypomethylation of LINE-1 repetitive elements in postmortem brains of patients with Dup15q compared to control or ASD patients [185]. In consonance with this study, recent whole genome bisulfite study revealed an exceedance of hypomethylated genes toward hypermethylated genes in SH-SY5Y cells after long-term exposure to PCB 95 [33]. Moreover, of the 255 genes hypomethylated with long-term PCB 95 exposure, 209 and 201 genes are in common with SH15M, a cell model for Dup15q, and SH15M cell exposed to PCB 95, respectively. Furthermore, histone variant H2A.Z, which is also related to epigenetic mechanisms, was found to be enriched in the gene body and alleged to the transcriptional instability of those hypomethylated genes [33]. Noticeably, transcriptional instability induced by PCB 95 exposure was similar to the observation in Dup15q postmortem brain samples [34]. Altogether, these studies suggest epigenetic effects of POPs, particularly PCBs, in the pathology of neurodevelopmental disorders.

In rat primary hippocampal neurons, treatment with PCB 95 upregulated miR-132 and increased spine density [186]. Although the effect of PCB 95 seems to be positive, it is important to notice that increased spine density is also observed in patients with ASD [187]. Moreover, miR-132 is known to downregulate $M e C P 2$, a key gene in neurodevelopment [188]; thus, the finding that PCB 95 upregulates miR-132 suggests a possible epigenetic mechanism behind PCBs neurotoxicity.

4.4. Heavy Metals. Exposure to heavy metals, particularly lead and mercury, is also known to alter DNA methylation. A study on methylation patterns in the promoter of $\mathrm{p} 16$, a gene related to neurodegeneration disorders, of 10 unexposed and 9 exposed individuals found that when unexposed group had an unmethylated pattern, the promoter of the p16 gene was partially methylated and fully methylated in the low-exposed and high-exposed groups, respectively [189]. A study reported for the first time that maternal exposure to 
lead was associated with alterations of DNA methylation in the umbilical cord blood [190]. In this study, the authors assessed maternal lead exposure using bone lead measurements and found a dose-response relationship between maternal patella lead concentrations and hypomethylation of LINE-1 repetitive elements and maternal tibia lead concentrations with hypomethylation of Alu sequence [190]. Regarding neurodevelopment, a study using mouse embryonic cortical neural stem cells found that $\mathrm{MeHg}$ treatment decreased mRNA levels of Dmnt3b but not Dnmt1 and Dnmt3a and induced global DNA hypomethylation [191]. Interestingly, the changes in gene expression and DNA methylation patterns were also observed in daughter cells, even after the treatment with $\mathrm{MeHg}$ was stopped, suggesting an inherited possibility of epigenetic modifications [191]. A recent study using human embryonic stem cells, neural progenitor stem cells, and neurons showed that treatment with lead affected the neural differentiation process; global DNA methylation changes were observed including both hypermethylation and hypomethylation [192].

\section{Epigenetic Inheritance}

A critical question arising from the research presented here is whether epigenetic alterations induced by environmental toxicants propagate to later generations. Environmental factors affect not only the person who was exposed but also the next and further generations. This phenomenon in which the acquired phenotype is transmitted is called "transgenerational inheritance." Classically, the constitutional change in the offspring is considered to be due to gene mutation. However, recent epigenetic studies suggest and support the idea that epigenetic changes could be inherited in the offspring, termed "transgenerational epigenetic inheritance" [193]. In fact, epigenetic modifications and mutations caused by environmental toxicants and nutritional disorders are maintained without being eliminated during the gametogenesis process and development after fertilization [194].

There are only a few, if any, studies that focus on the transgenerational epigenetic inheritance of environmental toxicant-induced alterations, especially, related to neurodevelopmental disorders. Although not spotlight environmental toxicants, animal models show that epigenetic effects caused by mental stress on parents can be transmitted to offspring. In addition, alterations of the epigenome in the neonatal brain induced by postnatal mental stress also occur in the spermatozoa. Furthermore, epigenomic alterations in brain and behavioral abnormalities were identified not only in children but also in grandchildren $[195,196]$. A comprehensive review by Babenko et al. on animal experiments concluded that alterations of miRNA expression and DNA methylation in the placenta and the brain due to stress, which are linked to greater risks of schizophrenia, ADHD, autism, and anxiety- or depression-related disorders, are transmitted to later generations [196]. Moreover, the transgenerational epigenetic inheritance is not limited to mental stress or neurodevelopment disorders; exposure to environmental toxicants, which act as endocrine disruptors, also changes DNA methylation in spermatozoa and transmits these changes to the next generation [197-200]. A study by Manikkam et al. investigated the effect of plastics (BPA, DEHP, and DBP mixture), dioxin, pesticides, and hydrocarbons on reproductive diseases and showed that phenotypes and changes in the differential methylation regions are remained in the F3 generation [199]. A further study on plastic mixtures by the same group revealed that the incidence of obesity and reproductive disorders, but not kidney and prostate diseases, was increased in the $\mathrm{F} 3$ generation and that changes in the differential methylation regions associated with obesity-related genes (namely, Tnfrsf12a, Esrra, Fgf19, Wnt10b, and Gdnf) were observed in the sperm of the F3 generation [200]. This observation supports the idea of transgenerational epigenetic inheritance; it suggests however that only some diseases that have the underlying epimutation can be inherited. In another study, Marczylo and colleagues found that smoking induced changes in miRNA expression in the spermatozoa; importantly, many of those miRNAs have HDACs as the predicted target genes [201]. More recently, although not studied in humans, BPA exposure has been shown to downregulate ten-eleven translocation (Tet) in the testes of Gobiocypris rarus [202]. Given that the TET protein family plays a critical role in regulating DNA methylation and in development [203], the downregulation of TETs due to BPA exposure may relate to methylome maintenance, and further studies need to look at the changes in genes that have roles in establishing DNA methylation.

However, the epigenetic inheritance theory should be interpreted with some caution. One possible explanation for epigenetic inheritance is that environmental factors can affect not only the pregnant mother (F0) who has been exposed but also her fetus (child-F1) and even the primordial germ cells (grandchild-F2) in the fetus, so that it is not the inheritance but the changes in the grandchild that are under the direct effect of grandparent exposure. Thus, in order to demonstrate true epigenetic inheritance, it is necessary to determine whether the influence will remain until the next generation (F3 or more) of the grandchild [204]. In view of our recent knowledge about epigenetic mechanisms, there is not enough evidence for supporting a conclusion on epigenetic inheritance-which is different from the inheritance of changes in DNA sequences, and is therefore by some authors referred to as "soft inheritance" [205-207].

\section{Conclusion and Perspective}

In summary, a number of research have pointed out the relationship between in utero exposure to environmental toxicants and an increase in the risk of neurodevelopmental disorders; several lines of research describe the changes in epigenetic markers, mainly on DNA methylation. Although some studies reveal epigenetic changes in neurodevelopment-related genes [158, 172], it is unclear whether there is a relationship between the epigenetic alterations induced by environmental toxicants and the related neurodevelopmental disorders. The DOHaD hypothesis in particular is mainly based on cohort epidemiological studies and proposes epigenetics as its underlying mechanism. It is 
therefore important for further cohort studies to focus on epigenetic alterations of specific genes related to neurodevelopmental disorders, in order to clarify the etiological pathways. One study on oxytocin receptor (OXTR) gene methylation, for example, found that higher OXTR methylation at birth, which is associated with maternal abnormal behavior, psychopathology, and substance use, is related to higher callous-unemotional traits [208].

In addition to epidemiological findings, which will point out the suspected changes in epigenome, experimental studies are in need to endorse such changes which are the consequence of environmental toxicants and are the inceptions of neurodevelopmental disorders. These studies, however, will have to face difficulties in modeling the neurodevelopment especially in human, the underlying genome that may have influence on the susceptibility to environmental toxicants, as well as the demonstration for epigenetic changes at desired targets. Animal models have been used in studies for phenotypes, pathological changes, and the inheritability due to prenatal and perinatal exposure of environmental toxicants as reviewed in Section 3.1 of this paper. The existed mouse model for neurodevelopmental disorders (review in [209]) further supplied indispensable tools for investigating effects of toxicants on vulnerable genotype. Nevertheless, the differences in the underlying biology between mouse and human may deceive the epigenetic alterations after exposure to environment toxicants. The recent advances in iPSCs would provide a powerful material to overcome those barriers. Moreover, iPSCs have advantages in both directions: they can be reprogrammed from patients, and thus obtain the susceptible genotype; reversely, they can be differentiated into many cell types including neuronal cells and represent the process of neural development although the differentiation methods are still different between laboratories. A recent study, for instance, using iPSC found that chlorpyrifos, a potential POP [210], downregulated of neurogenesis genes during neural differentiation process [211]. Genome editing has been in research for decades and used productively; epigenome editing, on the other hand, is just in its beginning. Recent progresses have implicated the utility of CRISPR (clustered regularly interspaced short palindromic repeats) and Cas9 (CRISPR-associated protein 9) fused with epigenetic modifying enzyme such as TET1, DNMT1, or histone acetyltransferase p300 for epigenome editing [212, 213]. The application of these tools will provide strong evidences for the relationship between epimutations and diseases.

In this review, we discuss several environmental toxicants: tobacco smoke, plastic-derived BPA and phthalates, POPs, and heavy metals, which have been under investigation for decades. Hand in hand with industry developments, more and more toxicants are identified. Further studies are thus needed to investigate the relationship between newly identified environmental toxicants such as particulate matter (PM2.5) and polycyclic aromatic hydrocarbons (PAH), which were recently suspected to have a negative impact on fetal development [214]. In addition to prenatal environmental toxicant exposure, a recent review focused on neurodevelopmental disorders, particularly ASD, ADHD, and schizophrenia, and described that the susceptibility of neurodevelopmental disorders to toxicant exposure is not limited to the gestational period but extends into the postnatal period [215]. As described earlier, epigenetic mechanisms, especially DNA methylation, are assumed to be the mechanism underlying the effect of toxicants on neurodevelopment. In mammals, DNA sequences are methylated mostly at CpG sites and the reprogramming process of $\mathrm{CpG}$ methylation occurs during the prenatal period [216]. However, non-CpG methylation $(\mathrm{CpA}, \mathrm{CpC}$, and $\mathrm{CpT})$ has also been detected, most abundant in stem cells and the brain of mice and humans, and found to have functions in regulating gene expression and possibly a role in genomic imprinting [217, 218]. Moreover, non-CpG methylation was found to be more abundant than $\mathrm{CpG}$ methylation in neurons and, interestingly, the percentage of non-CpG methylation sites increased during the postnatal period from 0 to 5 years [153]. Therefore, the role of non-CpG methylation in neurodevelopmental disorders is still unclear. As postnatal exposure to environmental toxicants also increases the risk of neurodevelopmental disorders, it is reasonable to consider the changes of DNA methylation at non-CpG sites under the effect of environmental toxicants. Lastly, as mentioned above, there is a lack of research focus on the transgenerational epigenetic inheritance of environmental toxicantinduced neurodevelopmental disorders. Gaining knowledge in the inheritability of epigenetic alteration by environmental toxicants will immensely aid in the progress of diagnosis and prevention of neurodevelopmental disorders.

\section{Conflicts of Interest}

The authors declare no conflict of interests.

\section{Acknowledgments}

The authors would like to thank Editage (www.editage.jp) for English language editing.

\section{References}

[1] J. C. Harris, "New classification for neurodevelopmental disorders in DSM-5," Current Opinion in Psychiatry, vol. 27, no. 2, pp. 95-97, 2014.

[2] B. Zablotsky, L. I. Black, M. J. Maenner, L. A. Schieve, and S. J. Blumberg, "Estimated prevalence of autism and other developmental disabilities following questionnaire changes in the 2014 National Health Interview Survey," National Health Statistics Reports, vol. 13, no. 87, pp. 1-20, 2015.

[3] D. L. Christensen, J. Baio, B. K. Van Naarden et al., "Prevalence and characteristics of autism spectrum disorder among children aged 8 years-Autism and Developmental Disabilities Monitoring Network, 11 sites, United States, 2012," MMWR Surveillance Summaries, vol. 65, no. 3, pp. 1-23, 2016.

[4] Autism, Developmental Disabilities Monitoring Network Surveillance Year Principal I, Centers for Disease C, Prevention, "Prevalence of autism spectrum disorders-autism and developmental disabilities monitoring network, 14 sites, 
United States, 2002," MMWR Surveillance Summaries, vol. 56, no. 1, pp. 12-28, 2007.

[5] Centers for Disease C, Prevention, "Increasing prevalence of parent-reported attention-deficit/hyperactivity disorder among children-United States, 2003 and 2007," MMWR. Morbidity and Mortality Weekly Report, vol. 59, no. 44, pp. 1439-1443, 2010.

[6] Centers for Disease C, Prevention, "Summary Health Statistics: National Health Interview Survey, 2015," National Center for Health Statistics, United States, 2015, https://ftp.cdc .gov/pub/Health_Statistics/NCHS/NHIS/SHS/2015_SHS_ Table_C-3.pdf.

[7] S. N. Hansen, D. E. Schendel, and E. T. Parner, "Explaining the increase in the prevalence of autism spectrum disorders: the proportion attributable to changes in reporting practices," JAMA Pediatrics, vol. 169, no. 1, pp. 56-62, 2015.

[8] Y. H. Neggers, "Increasing prevalence, changes in diagnostic criteria, and nutritional risk factors for autism spectrum disorders," ISRN Nutrition, vol. 2014, Article ID 514026, p. 14, 2014.

[9] K. M. Keyes, E. Susser, K. Cheslack-Postava, C. Fountain, K. Liu, and P. S. Bearman, "Cohort effects explain the increase in autism diagnosis among children born from 1992 to 2003 in California," International Journal of Epidemiology, vol. 41, no. 2, pp. 495-503, 2012.

[10] D. J. Barker, P. D. Gluckman, K. M. Godfrey, J. E. Harding, J. A. Owens, and J. S. Robinson, "Fetal nutrition and cardiovascular disease in adult life," Lancet, vol. 341, no. 8850, pp. 938-941, 1993.

[11] D. J. Barker and C. Osmond, "Infant mortality, childhood nutrition, and ischaemic heart disease in England and Wales," Lancet, vol. 1, no. 8489, pp. 1077-1081, 1986.

[12] D. J. Barker, P. D. Winter, C. Osmond, B. Margetts, and S. J. Simmonds, "Weight in infancy and death from ischaemic heart disease," Lancet, vol. 2, no. 8663, pp. 577-580, 1989.

[13] C. N. Hales, D. J. Barker, P. M. Clark et al., "Fetal and infant growth and impaired glucose tolerance at age 64," BMJ, vol. 303, no. 6809, pp. 1019-1022, 1991.

[14] D. J. Barker, "The origins of the developmental origins theory," Journal of Internal Medicine, vol. 261, no. 5, pp. 412-417, 2007.

[15] P. D. Gluckman and M. A. Hanson, "Living with the past: evolution, development, and patterns of disease," Science, vol. 305, no. 5691, pp. 1733-1736, 2004.

[16] P. D. Gluckman, C. Y. Seng, H. Fukuoka, A. S. Beedle, and M. A. Hanson, "Low birthweight and subsequent obesity in Japan," Lancet, vol. 369, no. 9567, pp. 1081-1082, 2007.

[17] D. St Clair, M. Xu, P. Wang et al., "Rates of adult schizophrenia following prenatal exposure to the Chinese famine of 1959-1961," JAMA, vol. 294, no. 5, pp. 557$562,2005$.

[18] R. C. Painter, S. R. de Rooij, P. M. Bossuyt et al., "Early onset of coronary artery disease after prenatal exposure to the Dutch famine," The American Journal of Clinical Nutrition, vol. 84, no. 2, pp. 322-327, 2006.

[19] E. A. DeVilbiss, R. M. Gardner, C. J. Newschaffer, and B. K. Lee, "Maternal folate status as a risk factor for autism spectrum disorders: a review of existing evidence," The British Journal of Nutrition, vol. 114, no. 5, pp. 663-672, 2015.

[20] J. Steenweg-de Graaff, S. J. Roza, E. A. Steegers et al., "Maternal folate status in early pregnancy and child emotional and behavioral problems: the Generation $\mathrm{R}$ Study," The American Journal of Clinical Nutrition, vol. 95, no. 6, pp. 1413-1421, 2012.

[21] H. Mazahery, C. A. Camargo Jr., C. Conlon, K. L. Beck, M. C. Kruger, and P. R. von Hurst, "Vitamin D and autism spectrum disorder: a literature review," Nutrients, vol. 8, no. 4, p. 236, 2016.

[22] K. M. Linnet, S. Dalsgaard, C. Obel et al., "Maternal lifestyle factors in pregnancy risk of attention deficit hyperactivity disorder and associated behaviors: review of the current evidence," The American Journal of Psychiatry, vol. 160, no. 6, pp. 1028-1040, 2003.

[23] D. Crafa and N. Warfa, "Maternal migration and autism risk: systematic analysis," International Review of Psychiatry, vol. 27, no. 1, pp. 64-71, 2015.

[24] Q. A. Class, K. M. Abel, A. S. Khashan et al., "Offspring psychopathology following preconception, prenatal and postnatal maternal bereavement stress," Psychological Medicine, vol. 44, no. 1, pp. 71-84, 2014.

[25] K. S. Betts, G. M. Williams, J. M. Najman, and R. Alati, "Maternal depressive, anxious, and stress symptoms during pregnancy predict internalizing problems in adolescence," Depression and Anxiety, vol. 31, no. 1, pp. 9-18, 2014.

[26] E. Sciberras, M. Mulraney, D. Silva, and D. Coghill, "Prenatal Risk Factors and the Etiology of ADHD-Review of Existing Evidence," Current Psychiatry Reports, vol. 19, no. 1, p. 1, 2017.

[27] A. E. Kalkbrenner, R. J. Schmidt, and A. C. Penlesky, "Environmental chemical exposures and autism spectrum disorders: a review of the epidemiological evidence," Current Problems in Pediatric and Adolescent Health Care, vol. 44, no. 10, pp. 277-318, 2014.

[28] S. L. Berger, T. Kouzarides, R. Shiekhattar, and A. Shilatifard, "An operational definition of epigenetics," Genes \& Development, vol. 23, no. 7, pp. 781-783, 2009.

[29] J. Peters, "The role of genomic imprinting in biology and disease: an expanding view," Nature Reviews. Genetics, vol. 15, no. 8, pp. 517-530, 2014.

[30] C. K. Cheon, "Genetics of Prader-Willi syndrome and Prader-Will-like syndrome," Annals of Pediatric Endocrinology \& Metabolism, vol. 21, no. 3, pp. 126-135, 2016.

[31] K. Buiting, C. Williams, and B. Horsthemke, "Angelman syndrome - insights into a rare neurogenetic disorder," Nature Reviews. Neurology, vol. 12, no. 10, pp. 584-593, 2016.

[32] L. Kalsner and S. J. Chamberlain, "Prader-Willi, Angelman, and 15q11-q13 duplication syndromes," Pediatric Clinics of North America, vol. 62, no. 3, pp. 587-606, 2015.

[33] K. W. Dunaway, M. S. Islam, R. L. Coulson et al., "Cumulative impact of polychlorinated biphenyl and large chromosomal duplications on dna methylation, chromatin, and expression of autism candidate genes," Cell Reports, vol. 17, no. 11, pp. 3035-3048, 2016.

[34] A. Hogart, K. N. Leung, N. J. Wang et al., "Chromosome 15q11-13 duplication syndrome brain reveals epigenetic alterations in gene expression not predicted from copy number," Journal of Medical Genetics, vol. 46, no. 2, pp. 86-93, 2009.

[35] H. A. Scoles, N. Urraca, S. W. Chadwick, L. T. Reiter, and J. M. Lasalle, "Increased copy number for methylated maternal $15 \mathrm{q}$ duplications leads to changes in gene and protein 
expression in human cortical samples," Mol Autism, vol. 2, no. 1, p. 19, 2011.

[36] G. L. Xu, T. H. Bestor, D. Bourc'his et al., "Chromosome instability and immunodeficiency syndrome caused by mutations in a DNA methyltransferase gene," Nature, vol. 402, no. 6758, pp. 187-191, 1999.

[37] T. Horii, D. Tamura, S. Morita, M. Kimura, and I. Hatada, "Generation of an ICF syndrome model by efficient genome editing of human induced pluripotent stem cells using the CRISPR system," International Journal of Molecular Sciences, vol. 14, no. 10, pp. 19774-19781, 2013.

[38] K. Martins-Taylor, D. I. Schroeder, J. M. LaSalle, M. Lalande, and R. H. Xu, "Role of DNMT3B in the regulation of early neural and neural crest specifiers," Epigenetics, vol. 7, no. 1, pp. 71-82, 2012.

[39] K. Huang, Z. Wu, Z. Liu et al., "Selective demethylation and altered gene expression are associated with ICF syndrome in human-induced pluripotent stem cells and mesenchymal stem cells," Human Molecular Genetics, vol. 23, no. 24, pp. 6448-6457, 2014.

[40] F. Neri, S. Rapelli, A. Krepelova et al., "Intragenic DNA methylation prevents spurious transcription initiation," Nature, vol. 543, no. 7643, pp. 72-77, 2017.

[41] S. Gatto, M. Gagliardi, M. Franzese et al., "ICF-specific DNMT3B dysfunction interferes with intragenic regulation of mRNA transcription and alternative splicing," Nucleic Acids Research, 2017, Epub ahead of print.

[42] K. Tatton-Brown, S. Seal, E. Ruark et al., "Mutations in the DNA methyltransferase gene DNMT3A cause an overgrowth syndrome with intellectual disability," Nature Genetics, vol. 46, no. 4, pp. 385-388, 2014.

[43] R. E. Amir, I. B. Van den Veyver, M. Wan, C. Q. Tran, U. Francke, and H. Y. Zoghbi, "Rett syndrome is caused by mutations in X-linked MECP2, encoding methyl-CpGbinding protein 2," Nature Genetics, vol. 23, no. 2, pp. 185$188,1999$.

[44] M. J. Lyst and A. Bird, "Rett syndrome: a complex disorder with simple roots," Nature Reviews. Genetics, vol. 16, no. 5, pp. 261-275, 2015.

[45] K. Miyake, T. Hirasawa, M. Soutome et al., "The protocadherins, PCDHB1 and PCDH7, are regulated by MeCP2 in neuronal cells and brain tissues: implication for pathogenesis of Rett syndrome," BMC Neuroscience, vol. 12, no. 1, p. 81, 2011.

[46] H. T. Chao, H. Y. Zoghbi, and C. Rosenmund, "MeCP2 controls excitatory synaptic strength by regulating glutamatergic synapse number," Neuron, vol. 56, no. 1, pp. 58-65, 2007.

[47] M. C. Marchetto, C. Carromeu, A. Acab et al., "A model for neural development and treatment of Rett syndrome using human induced pluripotent stem cells," Cell, vol. 143, no. 4, pp. 527-539, 2010.

[48] K. Y. Kim, E. Hysolli, and I. H. Park, "Neuronal maturation defect in induced pluripotent stem cells from patients with Rett syndrome," Proceedings of the National Academy of Sciences of the United States of America, vol. 108, no. 34, pp. 14169-14174, 2011.

[49] E. C. Williams, X. Zhong, A. Mohamed et al., "Mutant astrocytes differentiated from Rett syndrome patients-specific iPSCs have adverse effects on wild-type neurons," Human Molecular Genetics, vol. 23, no. 11, pp. 2968-2980, 2014.
[50] T. Andoh-Noda, W. Akamatsu, K. Miyake et al., "Differentiation of multipotent neural stem cells derived from Rett syndrome patients is biased toward the astrocytic lineage," Molecular Brain, vol. 8, no. 1, p. 31, 2015.

[51] H. Van Esch, M. Bauters, J. Ignatius et al., "Duplication of the MECP2 region is a frequent cause of severe mental retardation and progressive neurological symptoms in males," American Journal of Human Genetics, vol. 77, no. 3, pp. 442-453, 2005.

[52] M. Meins, J. Lehmann, F. Gerresheim et al., "Submicroscopic duplication in Xq28 causes increased expression of the MECP2 gene in a boy with severe mental retardation and features of Rett syndrome," Journal of Medical Genetics, vol. 42, no. 2, article e12, 2005.

[53] E. S. Na, E. D. Nelson, M. Adachi et al., "A mouse model for MeCP2 duplication syndrome: MeCP2 overexpression impairs learning and memory and synaptic transmission," The Journal of Neuroscience, vol. 32, no. 9, pp. 3109-3117, 2012.

[54] M. W. Gillman, D. Barker, D. Bier et al., "Meeting report on the 3rd International Congress on Developmental Origins of Health and Disease (DOHaD)," Pediatric Research, vol. 61, no. 5, Part 1, pp. 625-629, 2007.

[55] T. M. Edwards and J. P. Myers, "Environmental exposures and gene regulation in disease etiology," Environmental Health Perspectives, vol. 115, no. 9, pp. 1264-1270, 2007.

[56] B. A. Garcia, Z. Luka, L. V. Loukachevitch, N. V. Bhanu, and C. Wagner, "Folate deficiency affects histone methylation," Medical Hypotheses, vol. 88, pp. 63-67, 2016.

[57] K. A. Lillycrop, E. S. Phillips, A. A. Jackson, M. A. Hanson, and G. C. Burdge, "Dietary protein restriction of pregnant rats induces and folic acid supplementation prevents epigenetic modification of hepatic gene expression in the offspring," The Journal of Nutrition, vol. 135, no. 6, pp. 1382-1386, 2005.

[58] S. St-Cyr and P. O. McGowan, "Programming of stressrelated behavior and epigenetic neural gene regulation in mice offspring through maternal exposure to predator odor," Frontiers in Behavioral Neuroscience, vol. 9, p. 145, 2015.

[59] I. C. Weaver, "Epigenetic programming by maternal behavior and pharmacological intervention. Nature versus nurture: let's call the whole thing off," Epigenetics, vol. 2, no. 1, pp. 22-28, 2007.

[60] H. Palma-Gudiel, A. Cordova-Palomera, E. Eixarch, M. Deuschle, and L. Fananas, "Maternal psychosocial stress during pregnancy alters the epigenetic signature of the glucocorticoid receptor gene promoter in their offspring: a meta-analysis," Epigenetics, vol. 10, no. 10, pp. 893-902, 2015.

[61] E. C. Braithwaite, M. Kundakovic, P. G. Ramchandani, S. E. Murphy, and F. A. Champagne, "Maternal prenatal depressive symptoms predict infant $\mathrm{NR} 3 \mathrm{C} 1 \mathrm{~F}$ and $\mathrm{BDNF}$ IV DNA methylation," Epigenetics, vol. 10, no. 5, pp. 408-417, 2015.

[62] Centers for Disease C, Prevention, “The 2004 United States Surgeon General's Report: the health consequences of smoking," New South Wales Public Health Bulletin, vol. 15, no. 5-6, p. 107, 2004.

[63] C. M. Tiesler and J. Heinrich, "Prenatal nicotine exposure and child behavioural problems," European Child \& Adolescent Psychiatry, vol. 23, no. 10, pp. 913-929, 2014. 
[64] S. C. Curtin and T. J. Matthews, "Smoking prevalence and cessation before and during pregnancy: data from the birth certificate, 2014," National Vital Statistics Reports, vol. 65, no. 1, pp. 1-14, 2016.

[65] T. Alkam, H. C. Kim, M. Hiramatsu et al., "Evaluation of emotional behaviors in young offspring of C57BL/6J mice after gestational and/or perinatal exposure to nicotine in six different time-windows," Behavioural Brain Research, vol. 239, pp. 80-89, 2013.

[66] T. Alkam, H. C. Kim, T. Mamiya, K. Yamada, M. Hiramatsu, and T. Nabeshima, "Evaluation of cognitive behaviors in young offspring of C57BL/6J mice after gestational nicotine exposure during different time-windows," Psychopharmacology, vol. 230, no. 3, pp. 451-463, 2013.

[67] T. Schneider, N. Ilott, G. Brolese, L. Bizarro, P. J. Asherson, and I. P. Stolerman, "Prenatal exposure to nicotine impairs performance of the 5-choice serial reaction time task in adult rats," Neuropsychopharmacology, vol. 36, no. 5, pp. 1114-1125, 2011.

[68] K. Shah and D. K. Lahiri, "Cdk5 activity in the brain - multiple paths of regulation," Journal of Cell Science, vol. 127, Part 11, pp. 2391-2400, 2014.

[69] J. L. Zechel, J. L. Gamboa, A. G. Peterson, M. A. Puchowicz, W. R. Selman, and W. D. Lust, "Neuronal migration is transiently delayed by prenatal exposure to intermittent hypoxia," Birth Defects Research. Part B, Developmental and Reproductive Toxicology, vol. 74, no. 4, pp. 287-299, 2005.

[70] Y. Aoyama, K. Toriumi, A. Mouri et al., "Prenatal nicotine exposure impairs the proliferation of neuronal progenitors, leading to fewer glutamatergic neurons in the medial prefrontal cortex," Neuropsychopharmacology, vol. 41, no. 2, pp. 578-589, 2016.

[71] T. A. Slotkin, J. Card, A. Stadler, E. D. Levin, and F. J. Seidler, "Effects of tobacco smoke on PC12 cell neurodifferentiation are distinct from those of nicotine or benzo[a]pyrene," Neurotoxicology and Teratology, vol. 43, pp. 19-24, 2014.

[72] T. A. Slotkin, S. Skavicus, J. Card, E. D. Levin, and F. J. Seidler, "Amelioration strategies fail to prevent tobacco smoke effects on neurodifferentiation: nicotinic receptor blockade, antioxidants, methyl donors," Toxicology, vol. 333, pp. 6375, 2015.

[73] T. Geens, L. Goeyens, and A. Covaci, “Are potential sources for human exposure to bisphenol-A overlooked?" International Journal of Hygiene and Environmental Health, vol. 214, no. 5, pp. 339-347, 2011.

[74] P. Gimeno, C. Spinau, N. Lassu, A. F. Maggio, C. Brenier, and L. Lempereur, "Identification and quantification of bisphenol $\mathrm{A}$ and bisphenol B in polyvinylchloride and polycarbonate medical devices by gas chromatography with mass spectrometry," Journal of Separation Science, vol. 38, no. 21, pp. 37273734, 2015.

[75] E. Dursun, H. Fron-Chabouis, J. P. Attal, and A. Raskin, "Bisphenol A release: survey of the composition of dental composite resins," The Open Dentistry Journal, vol. 10, pp. 446-453, 2016.

[76] J. C. Gould, L. S. Leonard, S. C. Maness et al., "Bisphenol A interacts with the estrogen receptor alpha in a distinct manner from estradiol," Molecular and Cellular Endocrinology, vol. 142, no. 1-2, pp. 203-214, 1998.

[77] K. Moriyama, T. Tagami, T. Akamizu et al., "Thyroid hormone action is disrupted by bisphenol $\mathrm{A}$ as an antagonist," The Journal of Clinical Endocrinology and Metabolism, vol. 87, no. 11, pp. 5185-5190, 2002.

[78] J. Peretz, L. Vrooman, W. A. Ricke et al., "Bisphenol a and reproductive health: update of experimental and human evidence, 2007-2013," Environmental Health Perspectives, vol. 122, no. 8, pp. 775-786, 2014.

[79] X. H. Xu, J. Zhang, Y. M. Wang, Y. P. Ye, and Q. Q. Luo, "Perinatal exposure to bisphenol-A impairs learning-memory by concomitant down-regulation of N-methyl-D-aspartate receptors of hippocampus in male offspring mice," Hormones and Behavior, vol. 58, no. 2, pp. 326-333, 2010.

[80] X. Xu, L. Xie, X. Hong et al., "Perinatal exposure to bisphenol-A inhibits synaptogenesis and affects the synaptic morphological development in offspring male mice," Chemosphere, vol. 91, no. 8, pp. 1073-1081, 2013.

[81] K. A. McCaffrey, B. Jones, N. Mabrey, B. Weiss, S. H. Swan, and H. B. Patisaul, "Sex specific impact of perinatal bisphenol A (BPA) exposure over a range of orally administered doses on rat hypothalamic sexual differentiation," Neurotoxicology, vol. 36, pp. 55-62, 2013.

[82] J. Cao, J. A. Mickens, K. A. McCaffrey, S. M. Leyrer, and H. B. Patisaul, "Neonatal bisphenol A exposure alters sexually dimorphic gene expression in the postnatal rat hypothalamus," Neurotoxicology, vol. 33, no. 1, pp. 23-36, 2012.

[83] L. M. Wise, R. N. Sadowski, T. Kim, J. Willing, and J. M. Juraska, "Long-term effects of adolescent exposure to bisphenol A on neuron and glia number in the rat prefrontal cortex: differences between the sexes and cell type," Neurotoxicology, vol. 53, pp. 186-192, 2016.

[84] H. M. Koch and A. M. Calafat, "Human body burdens of chemicals used in plastic manufacture," Philosophical Transactions of the Royal Society of London. Series B, Biological Sciences, vol. 364, no. 1526, pp. 2063-2078, 2009.

[85] R. Hauser, S. Duty, L. Godfrey-Bailey, and A. M. Calafat, "Medications as a source of human exposure to phthalates," Environmental Health Perspectives, vol. 112, no. 6, pp. 751753, 2004.

[86] R. A. Rudel, J. M. Gray, C. L. Engel et al., "Food packaging and bisphenol A and bis(2-ethyhexyl) phthalate exposure: findings from a dietary intervention," Environmental Health Perspectives, vol. 119, no. 7, pp. 914-920, 2011.

[87] A. R. Singh, W. H. Lawrence, and J. Autian, "Maternal-fetal transfer of 14C-di-2-ethylhexyl phthalate and 14C-diethyl phthalate in rats," Journal of Pharmaceutical Sciences, vol. 64, no. 8, pp. 1347-1350, 1975.

[88] K. M. Main, G. K. Mortensen, M. M. Kaleva et al., "Human breast milk contamination with phthalates and alterations of endogenous reproductive hormones in infants three months of age," Environmental Health Perspectives, vol. 114, no. 2, pp. 270-276, 2006.

[89] T. Tanaka, "Reproductive and neurobehavioural toxicity study of bis(2-ethylhexyl) phthalate (DEHP) administered to mice in the diet," Food and Chemical Toxicology, vol. 40, no. 10, pp. 1499-1506, 2002.

[90] T. Chen, W. Yang, Y. Li, X. Chen, and S. Xu, "Mono-(2-ethylhexyl) phthalate impairs neurodevelopment: inhibition of proliferation and promotion of differentiation in PC12 cells," Toxicology Letters, vol. 201, no. 1, pp. 34-41, 2011.

[91] T. D. Aumann, "Environment- and activity-dependent dopamine neurotransmitter plasticity in the adult substantia nigra," Journal of Chemical Neuroanatomy, vol. 73, pp. 21-32, 2016. 
[92] Y. Xu, S. Agrawal, T. J. Cook, and G. T. Knipp, "Di-(2-ethylhexyl)-phthalate affects lipid profiling in fetal rat brain upon maternal exposure," Archives of Toxicology, vol. 81, no. 1, pp. 57-62, 2007.

[93] X. Li, L. Jiang, L. Cheng, and H. Chen, "Dibutyl phthalateinduced neurotoxicity in the brain of immature and mature rat offspring," Brain \& Development, vol. 36, no. 8, pp. 653660, 2014.

[94] A. K. Wojtowicz, K. A. Szychowski, A. Wnuk, and M. Kajta, "Dibutyl phthalate (DBP)-induced apoptosis and neurotoxicity are mediated via the aryl hydrocarbon receptor (AhR) but not by estrogen receptor alpha (ERalpha), estrogen receptor beta (ERbeta), or peroxisome proliferator-activated receptor gamma (PPARgamma) in mouse cortical neurons," Neurotoxicity Research, vol. 31, no. 1, pp. 77-89, 2017.

[95] M. Porta, E. Puigdomenech, F. Ballester et al., "Monitoring concentrations of persistent organic pollutants in the general population: the international experience," Environment International, vol. 34, no. 4, pp. 546-561, 2008.

[96] A. C. Gore, V. A. Chappell, S. E. Fenton et al., "EDC-2: The Endocrine Society's Second Scientific Statement on endocrine-disrupting chemicals," Endocrine Reviews, vol. 36, no. 6, pp. E1-E150, 2015.

[97] J. S. Park, A. Bergman, L. Linderholm et al., "Placental transfer of polychlorinated biphenyls, their hydroxylated metabolites and pentachlorophenol in pregnant women from eastern Slovakia," Chemosphere, vol. 70, no. 9, pp. 1676-1684, 2008.

[98] T. Fernandez-Cruz, E. Martinez-Carballo, and J. Simal-Gandara, "Perspective on pre- and post-natal agro-food exposure to persistent organic pollutants and their effects on quality of life," Environment International, vol. 100, pp. 79-101, 2017.

[99] V. M. Darras, "Endocrine disrupting polyhalogenated organic pollutants interfere with thyroid hormone signalling in the developing brain," Cerebellum, vol. 7, no. 1, pp. 26-37, 2008.

[100] S. S. Saeedi Saravi and A. R. Dehpour, "Potential role of organochlorine pesticides in the pathogenesis of neurodevelopmental, neurodegenerative, and neurobehavioral disorders: a review," Life Sciences, vol. 145, pp. 255-264, 2016.

[101] D. Yang and P. J. Lein, "Polychlorinated biphenyls increase apoptosis in the developing rat brain," Current Neurology, vol. 1, no. 1, pp. 70-76, 2010.

[102] A. A. Elnar, B. Diesel, F. Desor et al., "Neurodevelopmental and behavioral toxicity via lactational exposure to the sum of six indicator non-dioxin-like-polychlorinated biphenyls (summation operator6 NDL-PCBs) in mice," Toxicology, vol. 299, no. 1, pp. 44-54, 2012.

[103] N. Chen, J. Li, D. Li, Y. Yang, and D. He, "Chronic exposure to perfluorooctane sulfonate induces behavior defects and neurotoxicity through oxidative damages, in vivo and in vitro," PloS One, vol. 9, no. 11, article e113453, 2014.

[104] S. K. Choi, J. H. Kim, J. K. Park, K. M. Lee, E. Kim, and W. B. Jeon, "Cytotoxicity and inhibition of intercellular interaction in N2a neurospheroids by perfluorooctanoic acid and perfluorooctanesulfonic acid," Food and Chemical Toxicology, vol. 60 , pp. 520-529, 2013.

[105] Z. Li, Q. Liu, C. Liu et al., "Evaluation of PFOS-mediated neurotoxicity in rat primary neurons and astrocytes cultured separately or in co-culture," Toxicology In Vitro, vol. 38, pp. 77-90, 2017.
[106] N. Johansson, A. Fredriksson, and P. Eriksson, "Neonatal exposure to perfluorooctane sulfonate (PFOS) and perfluorooctanoic acid (PFOA) causes neurobehavioural defects in adult mice," Neurotoxicology, vol. 29, no. 1, pp. 160-169, 2008.

[107] M. Harada, "Minamata disease: methylmercury poisoning in Japan caused by environmental pollution," Critical Reviews in Toxicology, vol. 25, no. 1, pp. 1-24, 1995.

[108] M. Sakamoto, A. Kakita, K. Wakabayashi, H. Takahashi, A. Nakano, and H. Akagi, "Evaluation of changes in methylmercury accumulation in the developing rat brain and its effects: a study with consecutive and moderate dose exposure throughout gestation and lactation periods," Brain Research, vol. 949, no. 1-2, pp. 51-59, 2002.

[109] R. Cagiano, M. A. De Salvia, G. Renna et al., "Evidence that exposure to methyl mercury during gestation induces behavioral and neurochemical changes in offspring of rats," Neurotoxicology and Teratology, vol. 12, no. 1, pp. 23-28, 1990.

[110] D. Albores-Garcia, L. C. Acosta-Saavedra, A. J. Hernandez, M. J. Loera, and E. S. Calderon-Aranda, "Early developmental low-dose methylmercury exposure alters learning and memory in periadolescent but not young adult rats," BioMed Research International, vol. 2016, Article ID 6532108, p. 12, 2016.

[111] W. Liu, Z. Xu, Y. Deng, B. Xu, Y. Wei, and T. Yang, "Protective effects of memantine against methylmercury-induced glutamate dyshomeostasis and oxidative stress in rat cerebral cortex," Neurotoxicity Research, vol. 24, no. 3, pp. 320-337, 2013.

[112] F. Xu, S. Farkas, S. Kortbeek et al., "Mercury-induced toxicity of rat cortical neurons is mediated through N-methyl-Daspartate receptors," Molecular Brain, vol. 5, no. 1, p. 30, 2012.

[113] M. Lawton, M. Iqbal, M. Kontovraki, C. Lloyd Mills, and A. J. Hargreaves, "Reduced tubulin tyrosination as an early marker of mercury toxicity in differentiating N2a cells," Toxicology In Vitro, vol. 21, no. 7, pp. 1258-1261, 2007.

[114] P. Zanoli, G. Cannazza, and M. Baraldi, "Prenatal exposure to methyl mercury in rats: focus on changes in kynurenine pathway," Brain Research Bulletin, vol. 55, no. 2, pp. 235238, 2001.

[115] T. Vorvolakos, S. Arseniou, and M. Samakouri, "There is no safe threshold for lead exposure: alpha literature review," Psychiatriki, vol. 27, no. 3, pp. 204-214, 2016.

[116] N. Li, Z. L. Yu, L. Wang et al., "Early-life lead exposure affects the activity of TNF-alpha and expression of SNARE complex in hippocampus of mouse pups," Biological Trace Element Research, vol. 132, no. 1-3, pp. 227-238, 2009.

[117] M. Gassowska, I. Baranowska-Bosiacka, J. Moczydlowska et al., "Perinatal exposure to lead $(\mathrm{Pb})$ induces ultrastructural and molecular alterations in synapses of rat offspring," Toxicology, vol. 373, pp. 13-29, 2016.

[118] N. Li, G. Yang, Y. Wang et al., "Decreased IDE and IGF2 expression but increased Abeta40 in the cerebral cortex of mouse pups by early life lead exposure," Brain Research Bulletin, vol. 121, pp. 84-90, 2016.

[119] H. Yu, Y. Liao, T. Li et al., "Alterations of synaptic proteins in the hippocampus of mouse offspring induced by developmental lead exposure," Molecular Neurobiology, vol. 53, no. 10 , pp. 6786-6798, 2016. 
[120] A. Rahman, B. J. Brew, and G. J. Guillemin, "Lead dysregulates serine/threonine protein phosphatases in human neurons," Neurochemical Research, vol. 36, no. 2, pp. 195-204, 2011.

[121] B. Eskenazi and R. Castorina, "Association of prenatal maternal or postnatal child environmental tobacco smoke exposure and neurodevelopmental and behavioral problems in children," Environmental Health Perspectives, vol. 107, no. 12, pp. 991-1000, 1999.

[122] K. Polanska, J. Jurewicz, and W. Hanke, "Smoking and alcohol drinking during pregnancy as the risk factors for poor child neurodevelopment - a review of epidemiological studies," International Journal of Occupational Medicine and Environmental Health, vol. 28, no. 3, pp. 419-443, 2015.

[123] L. M. Gatzke-Kopp and T. P. Beauchaine, "Direct and passive prenatal nicotine exposure and the development of externalizing psychopathology," Child Psychiatry and Human Development, vol. 38, no. 4, pp. 255-269, 2007.

[124] K. M. Keyes, G. Davey Smith, and E. Susser, "Associations of prenatal maternal smoking with offspring hyperactivity: causal or confounded?" Psychological Medicine, vol. 44, no. 4, pp. 857-867, 2014.

[125] K. Langley, J. Heron, G. D. Smith, and A. Thapar, "Maternal and paternal smoking during pregnancy and risk of ADHD symptoms in offspring: testing for intrauterine effects," American Journal of Epidemiology, vol. 176, no. 3, pp. 261268, 2012.

[126] K. Latimer, P. Wilson, J. Kemp et al., "Disruptive behaviour disorders: a systematic review of environmental antenatal and early years risk factors," Child: Care, Health and Development, vol. 38, no. 5, pp. 611-628, 2012.

[127] Y. Nomura, D. J. Marks, and J. M. Halperin, "Prenatal exposure to maternal and paternal smoking on attention deficit hyperactivity disorders symptoms and diagnosis in offspring," The Journal of Nervous and Mental Disease, vol. 198, no. 9, pp. 672-678, 2010.

[128] C. M. Tiesler, C. M. Chen, S. Sausenthaler et al., "Passive smoking and behavioural problems in children: results from the LISAplus prospective birth cohort study," Environmental Research, vol. 111, no. 8, pp. 1173-1179, 2011.

[129] M. Melchior, R. Hersi, J. van der Waerden et al., "Maternal tobacco smoking in pregnancy and children's socioemotional development at age 5: The EDEN mother-child birth cohort study," European Psychiatry, vol. 30, no. 5, pp. 562-568, 2015.

[130] P. Joelsson, R. Chudal, A. Talati, A. Suominen, A. S. Brown, and A. Sourander, "Prenatal smoking exposure and neuropsychiatric comorbidity of ADHD: a Finnish nationwide population-based cohort study," BMC Psychiatry, vol. 16, no. 1, p. 306, 2016.

[131] J. L. Zhu, J. Olsen, Z. Liew, J. Li, J. Niclasen, and C. Obel, "Parental smoking during pregnancy and ADHD in children: the Danish national birth cohort," Pediatrics, vol. 134, no. 2, pp. e382-e388, 2014.

[132] H. A. Browne, A. Modabbernia, J. D. Buxbaum et al., "Prenatal maternal smoking and increased risk for Tourette syndrome and chronic tic disorders," Journal of the American Academy of Child and Adolescent Psychiatry, vol. 55, no. 9, pp. 784-791, 2016.

[133] A. E. Kalkbrenner, J. M. Braun, M. S. Durkin et al., "Maternal smoking during pregnancy and the prevalence of autism spectrum disorders, using data from the autism and developmental disabilities monitoring network," Environmental Health Perspectives, vol. 120, no. 7, pp. 1042-1048, 2012.

[134] S. Tang, Y. Wang, X. Gong, and G. Wang, "A metaanalysis of maternal smoking during pregnancy and autism spectrum disorder risk in offspringInternational Journal of Environmental Research and Public Health, vol. 12, no. 9, pp. 10418-10431, 2015.

[135] J. M. Braun, A. E. Kalkbrenner, A. M. Calafat et al., "Impact of early-life bisphenol A exposure on behavior and executive function in children," Pediatrics, vol. 128, no. 5, pp. 873882, 2011.

[136] S. F. Evans, R. W. Kobrosly, E. S. Barrett et al., "Prenatal bisphenol A exposure and maternally reported behavior in boys and girls," Neurotoxicology, vol. 45, pp. 91-99, 2014.

[137] F. Perera, J. Vishnevetsky, J. B. Herbstman et al., "Prenatal bisphenol A exposure and child behavior in an inner-city cohort," Environmental Health Perspectives, vol. 120, no. 8, pp. 1190-1194, 2012.

[138] E. L. Roen, Y. Wang, A. M. Calafat et al., "Bisphenol A exposure and behavioral problems among inner city children at 7-9 years of age," Environmental Research, vol. 142, pp. 739-745, 2015.

[139] M. Casas, J. Forns, D. Martinez et al., "Exposure to bisphenol A during pregnancy and child neuropsychological development in the INMA-Sabadell cohort," Environmental Research, vol. 142, pp. 671-679, 2015.

[140] K. Polanska, D. Ligocka, W. Sobala, and W. Hanke, "Phthalate exposure and child development: the Polish Mother and Child Cohort Study," Early Human Development, vol. 90, no. 9, pp. 477-485, 2014.

[141] Y. J. Lien, H. Y. Ku, P. H. Su et al., "Prenatal exposure to phthalate esters and behavioral syndromes in children at 8 years of age: Taiwan Maternal and Infant Cohort Study," Environmental Health Perspectives, vol. 123, no. 1, pp. 95-100, 2015.

[142] M. Minatoya, S. Naka Jima, S. Sasaki et al.Effects of prenatal phthalate exposure on thyroid hormone levels, mental and psychomotor development of infants: The Hokkaido Study on Environment and Children's Health," Science of the Total Environment, vol. 565, pp. 1037-1043, 2016.

[143] M. Strom, S. Hansen, S. F. Olsen et al., "Persistent organic pollutants measured in maternal serum and offspring neurodevelopmental outcomes-a prospective study with longterm follow-up," Environment International, vol. 68, pp. 41-48, 2014.

[144] A. Kyriklaki, M. Vafeiadi, M. Kampouri et al., "Prenatal exposure to persistent organic pollutants in association with offspring neuropsychological development at 4years of age: the Rhea mother-child cohort, Crete, Greece," Environment International, vol. 97, pp. 204-211, 2016.

[145] Y. Oulhote, U. Steuerwald, F. Debes, P. Weihe, and P. Grandjean, "Behavioral difficulties in 7-year old children in relation to developmental exposure to perfluorinated alkyl substances," Environment International, vol. 97, pp. 237-245, 2016.

[146] J. Neugebauer, J. Wittsiepe, M. Kasper-Sonnenberg, N. Schoneck, A. Scholmerich, and M. Wilhelm, "The influence of low level pre- and perinatal exposure to PCDD/Fs, PCBs, and lead on attention performance and attention-related behavior among German school-aged children: results from the Duisburg Birth Cohort Study," International 
Journal of Hygiene and Environmental Health, vol. 218, no. 1, pp. 153-162, 2015.

[147] H. Goudarzi, S. Nakajima, T. Ikeno et al., "Prenatal exposure to perfluorinated chemicals and neurodevelopment in early infancy: The Hokkaido Study," Science of the Total Environment, vol. 541, pp. 1002-1010, 2016.

[148] M. Rodriguez-Barranco, M. Lacasana, C. Aguilar-Garduno et al., "Association of arsenic, cadmium and manganese exposure with neurodevelopment and behavioural disorders in children: a systematic review and meta-analysis," Science of the Total Environment, vol. 454-455, pp. 562577, 2013.

[149] J. Liu, X. Liu, W. Wang et al., "Blood lead concentrations and children's behavioral and emotional problems: a cohort study," JAMA Pediatrics, vol. 168, no. 8, pp. 737-745, 2014.

[150] E. G. Rodrigues, D. C. Bellinger, L. Valeri et al., "Neurodevelopmental outcomes among 2- to 3-year-old children in Bangladesh with elevated blood lead and exposure to arsenic and manganese in drinking water," Environmental Health, vol. 15, no. 1, p. 44, 2016.

[151] P. L. Tran, V. Lehti, K. M. Lampi et al., "Smoking during pregnancy and risk of autism spectrum disorder in a Finnish National Birth Cohort," Paediatric and Perinatal Epidemiology, vol. 27, no. 3, pp. 266-274, 2013.

[152] M. Ejaredar, E. C. Nyanza, K. Ten Eycke, and D. Dewey, "Phthalate exposure and childrens neurodevelopment: a systematic review," Environmental Research, vol. 142, pp. 51-60, 2015.

[153] R. Lister, E. A. Mukamel, J. R. Nery et al., "Global epigenomic reconfiguration during mammalian brain development," Science, vol. 341, no. 6146, article 1237905, 2013.

[154] D. Schubeler, "Function and information content of DNA methylation," Nature, vol. 517, no. 7534, pp. 321-326, 2015.

[155] D. Y. Liu, X. M. Shen, F. F. Yuan et al., "The physiology of BDNF and its relationship with ADHD," Molecular Neurobiology, vol. 52, no. 3, pp. 1467-1476, 2015.

[156] D. M. Halepoto, S. Bashir, and L. AL-Ayadhi, "Possible role of brain-derived neurotrophic factor (BDNF) in autism spectrum disorder: current status," Journal of the College of Physicians and Surgeons-Pakistan, vol. 24, no. 4, pp. 274278, 2014.

[157] J. L. Larimore, C. A. Chapleau, S. Kudo, A. Theibert, A. K. Percy, and L. Pozzo-Miller, "Bdnf overexpression in hippocampal neurons prevents dendritic atrophy caused by Rett-associated MECP2 mutations," Neurobiology of Disease, vol. 34, no. 2, pp. 199-211, 2009.

[158] M. Toledo-Rodriguez, S. Lotfipour, G. Leonard et al., "Maternal smoking during pregnancy is associated with epigenetic modifications of the brain-derived neurotrophic factor-6 exon in adolescent offspring," American Journal of Medical Genetics. Part B, Neuropsychiatric Genetics, vol. 153B, no. 7, pp. 1350-1354, 2010.

[159] M. Suter, J. Ma, A. Harris et al., "Maternal tobacco use modestly alters correlated epigenome-wide placental DNA methylation and gene expression," Epigenetics, vol. 6, no. 11, pp. 1284-1294, 2011.

[160] L. R. Stroud, G. D. Papandonatos, A. L. Salisbury et al., "Epigenetic regulation of placental NR3C1: mechanism underlying prenatal programming of infant neurobehavior by maternal smoking?" Child Development, vol. 87, no. 1, pp. 49-60, 2016.
[161] J. D. Flom, J. S. Ferris, Y. Liao et al., "Prenatal smoke exposure and genomic DNA methylation in a multiethnic birth cohort," Cancer Epidemiology, Biomarkers \& Prevention, vol. 20, no. 12, pp. 2518-2523, 2011.

[162] V. K. Rakyan, T. A. Down, D. J. Balding, and S. Beck, "Epigenome-wide association studies for common human diseases," Nature Reviews. Genetics, vol. 12, no. 8, pp. 529-541, 2011.

[163] B. R. Joubert, S. E. Haberg, R. M. Nilsen et al., " $450 \mathrm{~K}$ epigenome-wide scan identifies differential DNA methylation in newborns related to maternal smoking during pregnancy," Environmental Health Perspectives, vol. 120, no. 10, pp. 1425-1431, 2012.

[164] B. Novakovic, J. Ryan, N. Pereira, B. Boughton, J. M. Craig, and R. Saffery, "Postnatal stability, tissue, and time specific effects of AHRR methylation change in response to maternal smoking in pregnancy," Epigenetics, vol. 9, no. 3, pp. 377386, 2014.

[165] P. Kaur, A. Armugam, and K. Jeyaseelan, "MicroRNAs in neurotoxicity," Journal of Toxicology, vol. 2012, Article ID 870150, p. 15, 2012.

[166] M. A. Maccani, M. Avissar-Whiting, C. E. Banister, B. McGonnigal, J. F. Padbury, and C. J. Marsit, "Maternal cigarette smoking during pregnancy is associated with downregulation of miR-16, miR-21, and miR-146a in the placenta," Epigenetics, vol. 5, no. 7, pp. 583-589, 2010.

[167] M. A. Maccani, J. F. Padbury, B. M. Lester, V. S. Knopik, and C. J. Marsit, "Placental miRNA expression profiles are associated with measures of infant neurobehavioral outcomes," Pediatric Research, vol. 74, no. 3, pp. 272-278, 2013.

[168] J. Sollome, E. Martin, P. Sethupathy, and R. C. Fry, "Environmental contaminants and microRNA regulation: transcription factors as regulators of toxicant-altered microRNA expression," Toxicology and Applied Pharmacology, vol. 312, pp. 61-66, 2016.

[169] T. Yaoi, K. Itoh, K. Nakamura, H. Ogi, Y. Fujiwara, and S. Fushiki, "Genome-wide analysis of epigenomic alterations in fetal mouse forebrain after exposure to low doses of bisphenol A," Biochemical and Biophysical Research Communications, vol. 376, no. 3, pp. 563-567, 2008.

[170] M. Kundakovic, K. Gudsnuk, J. B. Herbstman, D. Tang, F. P. Perera, and F. A. Champagne, "DNA methylation of BDNF as a biomarker of early-life adversity," Proceedings of the National Academy of Sciences of the United States of America, vol. 112, no. 22, pp. 6807-6813, 2015.

[171] J. T. Wolstenholme, J. A. Taylor, S. R. Shetty, M. Edwards, J. J. Connelly, and E. F. Rissman, "Gestational exposure to low dose bisphenol A alters social behavior in juvenile mice," PloS One, vol. 6, no. 9, article e25448, 2011.

[172] M. Kundakovic, K. Gudsnuk, B. Franks et al., "Sex-specific epigenetic disruption and behavioral changes following lowdose in utero bisphenol A exposure," Proceedings of the National Academy of Sciences of the United States of America, vol. 110, no. 24, pp. 9956-9961, 2013.

[173] S. C. Kang and B. M. Lee, "DNA methylation of estrogen receptor alpha gene by phthalates," Journal of Toxicology and Environmental Health. Part A, vol. 68, no. 23-24, pp. 1995-2003, 2005.

[174] C. Faulk, J. H. Kim, O. S. Anderson et al., "Detection of differential DNA methylation in repetitive DNA of mice and humans perinatally exposed to bisphenol A," Epigenetics, vol. 11, no. 7, pp. 489-500, 2016. 
[175] G. Guffanti, S. Gaudi, T. Klengel et al., "LINE1 insertions as a genomic risk factor for schizophrenia: preliminary evidence from an affected family," American Journal of Medical Genetics. Part B, Neuropsychiatric Genetics, vol. 171, no. 4, pp. 534-545, 2016.

[176] J. B. Vincent, S. I. Horike, S. Choufani et al., "An inversion inv(4)(p12-p15.3) in autistic siblings implicates the 4p GABA receptor gene cluster," Journal of Medical Genetics, vol. 43, no. 5, pp. 429-434, 2006.

[177] M. Avissar-Whiting, K. R. Veiga, K. M. Uhl et al., "Bisphenol A exposure leads to specific microRNA alterations in placental cells," Reproductive Toxicology, vol. 29, no. 4, pp. 401-406, 2010.

[178] J. LaRocca, A. M. Binder, T. F. McElrath, and K. B. Michels, "First-trimester urine concentrations of phthalate metabolites and phenols and placenta miRNA expression in a cohort of U.S. women," Environmental Health Perspectives, vol. 124, no. 3, pp. 380-387, 2016.

[179] M. Yeo, K. Berglund, M. Hanna et al., "Bisphenol A delays the perinatal chloride shift in cortical neurons by epigenetic effects on the Kcc2 promoter," Proceedings of the National Academy of Sciences of the United States of America, vol. 110, no. 11, pp. 4315-4320, 2013.

[180] K. Kaila, T. J. Price, J. A. Payne, M. Puskarjov, and J. Voipio, "Cation-chloride cotransporters in neuronal development, plasticity and disease," Nature Reviews. Neuroscience, vol. 15, no. 10, pp. 637-654, 2014.

[181] J. A. Rusiecki, A. Baccarelli, V. Bollati, L. Tarantini, L. E. Moore, and E. C. Bonefeld-Jorgensen, "Global DNA hypomethylation is associated with high serum-persistent organic pollutants in Greenlandic Inuit," Environmental Health Perspectives, vol. 116, no. 11, pp. 1547-1552, 2008.

[182] K. Y. Kim, D. S. Kim, S. K. Lee et al., “Association of low-dose exposure to persistent organic pollutants with global DNA hypomethylation in healthy Koreans," Environmental Health Perspectives, vol. 118, no. 3, pp. 370-374, 2010.

[183] H. Itoh, M. Iwasaki, Y. Kasuga et al., "Association between serum organochlorines and global methylation level of leukocyte DNA among Japanese women: a cross-sectional study," Science of the Total Environment, vol. 490, pp. 603-609, 2014.

[184] L. Lind, J. Penell, K. Luttropp et al., "Global DNA hypermethylation is associated with high serum levels of persistent organic pollutants in an elderly population," Environment International, vol. 59, pp. 456-461, 2013.

[185] M. M. Mitchell, R. Woods, L. H. Chi et al., "Levels of select PCB and PBDE congeners in human postmortem brain reveal possible environmental involvement in 15q11-q13 duplication autism spectrum disorder," Environmental and Molecular Mutagenesis, vol. 53, no. 8, pp. 589-598, 2012.

[186] A. Lesiak, M. Zhu, H. Chen et al., "The environmental neurotoxicant PCB 95 promotes synaptogenesis via ryanodine receptor-dependent miR132 upregulation," The Journal of Neuroscience, vol. 34, no. 3, pp. 717-725, 2014.

[187] J. J. Hutsler and H. Zhang, "Increased dendritic spine densities on cortical projection neurons in autism spectrum disorders," Brain Research, vol. 1309, pp. 83-94, 2010.

[188] M. E. Klein, D. T. Lioy, L. Ma, S. Impey, G. Mandel, and R. H. Goodman, "Homeostatic regulation of $\mathrm{MeCP} 2$ expression by a CREB-induced microRNA," Nature Neuroscience, vol. 10, no. 12, pp. 1513-1514, 2007.
[189] L. Kovatsi, E. Georgiou, A. Ioannou et al., "p16 promoter methylation in $\mathrm{Pb} 2+-$ exposed individuals," Clinical Toxicology (Philadelphia, Pa.), vol. 48, no. 2, pp. 124-128, 2010.

[190] J. R. Pilsner, H. Hu, A. Ettinger et al., "Influence of prenatal lead exposure on genomic methylation of cord blood DNA," Environmental Health Perspectives, vol. 117, no. 9, pp. 1466-1471, 2009.

[191] R. Bose, N. Onishchenko, K. Edoff, A. M. Janson Lang, and S. Ceccatelli, "Inherited effects of low-dose exposure to methylmercury in neural stem cells," Toxicological Sciences, vol. 130, no. 2, pp. 383-390, 2012.

[192] M. C. Senut, A. Sen, P. Cingolani, A. Shaik, S. J. Land, and D. M. Ruden, "Lead exposure disrupts global DNA methylation in human embryonic stem cells and alters their neuronal differentiation," Toxicological Sciences, vol. 139, no. 1, pp. 142-161, 2014.

[193] M. K. Skinner, M. Manikkam, and C. Guerrero-Bosagna, "Epigenetic transgenerational actions of environmental factors in disease etiology," Trends in Endocrinology and Metabolism, vol. 21, no. 4, pp. 214-222, 2010.

[194] L. Daxinger and E. Whitelaw, "Understanding transgenerational epigenetic inheritance via the gametes in mammals," Nature Reviews. Genetics, vol. 13, no. 3, pp. 153-162, 2012.

[195] T. B. Franklin, H. Russig, I. C. Weiss et al., "Epigenetic transmission of the impact of early stress across generations," Biological Psychiatry, vol. 68, no. 5, pp. 408-415, 2010.

[196] O. Babenko, I. Kovalchuk, and G. A. Metz, "Stress-induced perinatal and transgenerational epigenetic programming of brain development and mental health," Neuroscience and Biobehavioral Reviews, vol. 48, pp. 70-91, 2015.

[197] M. D. Anway and M. K. Skinner, "Epigenetic programming of the germ line: effects of endocrine disruptors on the development of transgenerational disease," Reproductive Biomedicine Online, vol. 16, no. 1, pp. 23-25, 2008.

[198] Z. Mao, W. Xia, H. Chang, W. Huo, Y. Li, and S. Xu, "Paternal BPA exposure in early life alters Igf2 epigenetic status in sperm and induces pancreatic impairment in rat offspring," Toxicology Letters, vol. 238, no. 3, pp. 30-38, 2015.

[199] M. Manikkam, C. Guerrero-Bosagna, R. Tracey, M. M. Haque, and M. K. Skinner, "Transgenerational actions of environmental compounds on reproductive disease and identification of epigenetic biomarkers of ancestral exposures," PloS One, vol. 7, no. 2, article e31901, 2012.

[200] M. Manikkam, R. Tracey, C. Guerrero-Bosagna, and M. K. Skinner, "Plastics derived endocrine disruptors (BPA, DEHP and DBP) induce epigenetic transgenerational inheritance of obesity, reproductive disease and sperm epimutations," PloS One, vol. 8, no. 1, article e55387, 2013.

[201] E. L. Marczylo, A. A. Amoako, J. C. Konje, T. W. Gant, and T. H. Marczylo, "Smoking induces differential miRNA expression in human spermatozoa: a potential transgenerational epigenetic concern?" Epigenetics, vol. 7, no. 5, pp. 432-439, 2012.

[202] C. Yuan, Y. Zhang, Y. Liu, S. Wang, and Z. Wang, "DNA demethylation mediated by down-regulated TETs in the testes of rare minnow Gobiocypris rarus under bisphenol A exposure," Chemosphere, vol. 171, pp. 355-361, 2016.

[203] S. R. Kinney and S. Pradhan, "Ten eleven translocation enzymes and 5-hydroxymethylation in mammalian development and cancer," Advances in Experimental Medicine and Biology, vol. 754, pp. 57-79, 2013. 
[204] E. Heard and R. A. Martienssen, "Transgenerational epigenetic inheritance: myths and mechanisms," Cell, vol. 157, no. 1, pp. 95-109, 2014.

[205] M. A. Hanson, F. M. Low, and P. D. Gluckman, "Epigenetic epidemiology: the rebirth of soft inheritance," Annals of Nutrition \& Metabolism, vol. 58, Supplement 2, pp. 815, 2011.

[206] E. J. Richards, "Inherited epigenetic variation-revisiting soft inheritance," Nature Reviews. Genetics, vol. 7, no. 5, pp. 395-401, 2006.

[207] T. E. Dickins and Q. Rahman, "The extended evolutionary synthesis and the role of soft inheritance in evolution," Proceedings of the Biological Sciences, vol. 279, no. 1740, pp. 2913-2921, 2012.

[208] C. A. Cecil, L. J. Lysenko, S. R. Jaffee et al., "Environmental risk, oxytocin receptor gene (OXTR) methylation and youth callous-unemotional traits: a 13-year longitudinal study," Molecular Psychiatry, vol. 19, no. 10, pp. 1071-1077, 2014.

[209] J. N. Crawley, "Translational animal models of autism and neurodevelopmental disorders," Dialogues in Clinical Neuroscience, vol. 14, no. 3, pp. 293-305, 2012.

[210] J. P. Giesy, K. R. Solomon, D. Mackay, and J. Anderson, "Evaluation of evidence that the organophosphorus insecticide chlorpyrifos is a potential persistent organic pollutant (POP) or persistent, bioaccumulative, and toxic (PBT)," Environmental Sciences Europe, vol. 26, no. 1, p. 29, 2014.

[211] S. Yamada, Y. Kubo, D. Yamazaki, Y. Sekino, and Y. Kanda, "Chlorpyrifos inhibits neural induction via Mfn1-mediated mitochondrial dysfunction in human induced pluripotent stem cells," Scientific Reports, vol. 7, p. 40925, 2017.

[212] I. B. Hilton, A. M. D'Ippolito, C. M. Vockley et al., "Epigenome editing by a CRISPR-Cas9-based acetyltransferase activates genes from promoters and enhancers," Nature Biotechnology, vol. 33, no. 5, pp. 510-517, 2015.

[213] X. S. Liu, H. Wu, X. Ji et al., "Editing DNA Methylation in the mammalian genome," Cell, vol. 167, no. 1, pp. 233-247.e217, 2016.

[214] W. A. Jedrychowski, R. Majewska, J. D. Spengler, D. Camann, E. L. Roen, and F. P. Perera, "Prenatal exposure to fine particles and polycyclic aromatic hydrocarbons and birth outcomes: a two-pollutant approach," International Archives of Occupational and Environmental Health, vol. 90, no. 3, pp. 255-264, 2017.

[215] D. B. Heyer and R. M. Meredith, "Environmental toxicology: sensitive periods of development and neurodevelopmental disorders," Neurotoxicology, vol. 58, pp. 23-41, 2016.

[216] S. Seisenberger, J. R. Peat, T. A. Hore, F. Santos, W. Dean, and W. Reik, "Reprogramming DNA methylation in the mammalian life cycle: building and breaking epigenetic barriers," Philosophical Transactions of the Royal Society of London. Series B, Biological Sciences, vol. 368, no. 1609, p. 20110330, 2013.

[217] M. J. Ziller, F. Muller, J. Liao et al., "Genomic distribution and inter-sample variation of non-CpG methylation across human cell types," PLoS Genetics, vol. 7, no. 12, article e1002389, 2011.

[218] V. Patil, R. L. Ward, and L. B. Hesson, "The evidence for functional non-CpG methylation in mammalian cells," Epigenetics, vol. 9, no. 6, pp. 823-828, 2014. 

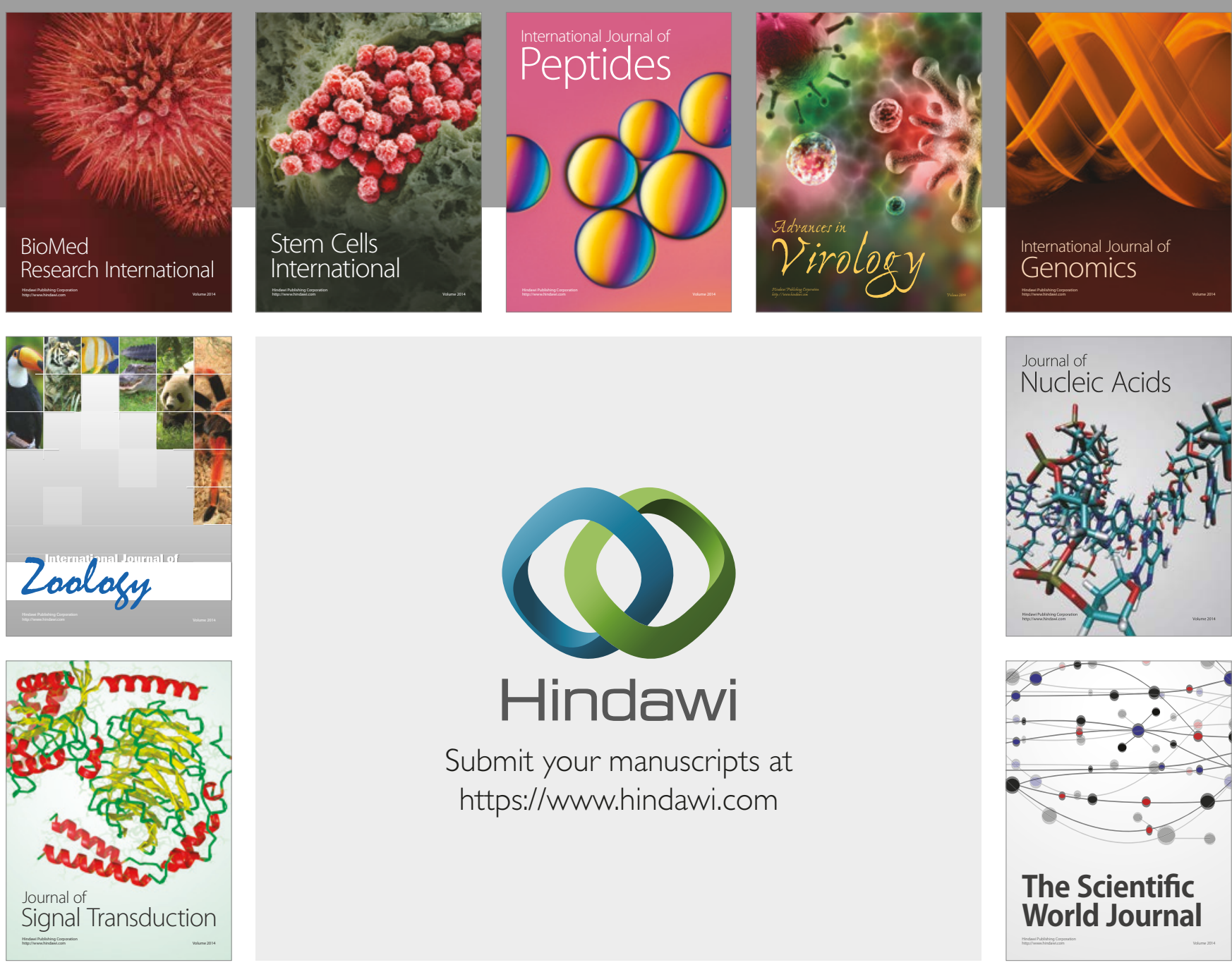

Submit your manuscripts at

https://www.hindawi.com
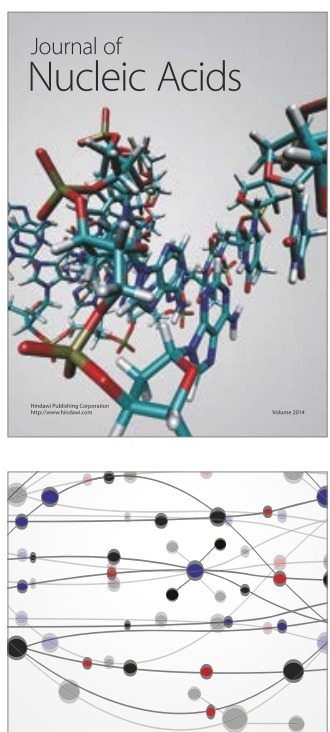

The Scientific World Journal

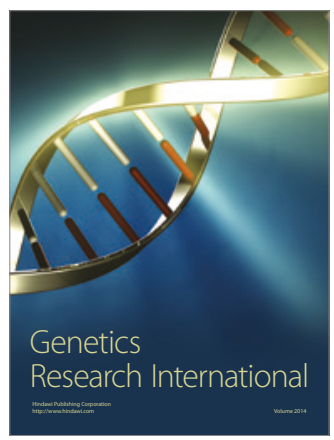

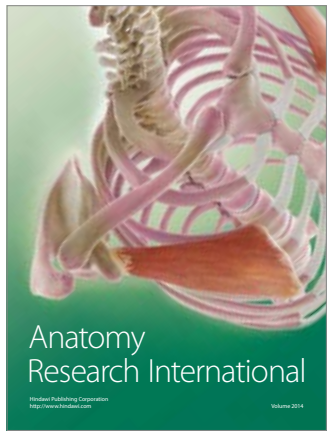

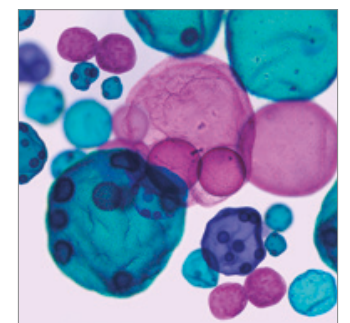

International Journal of Microbiology
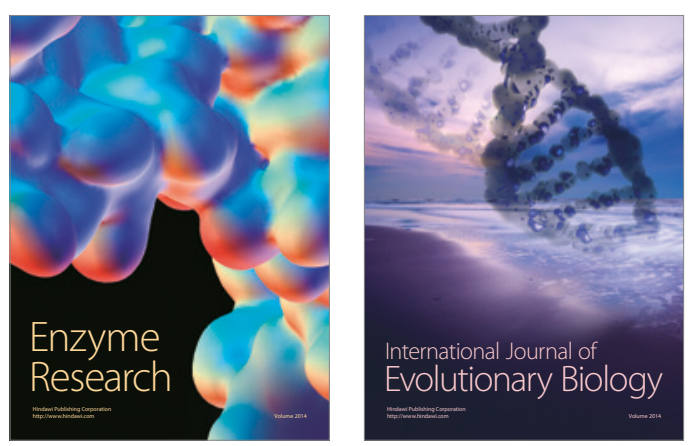
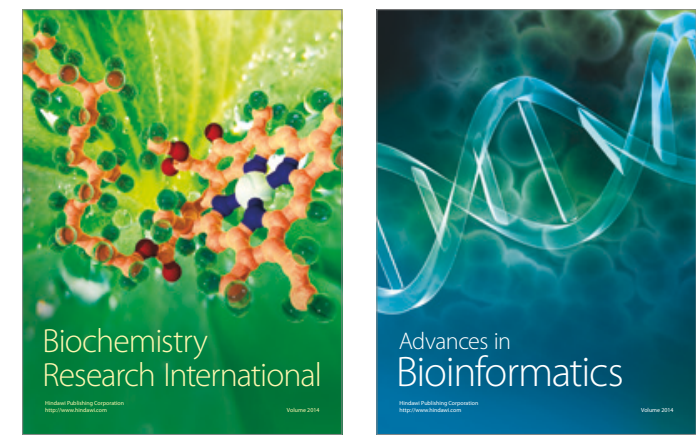

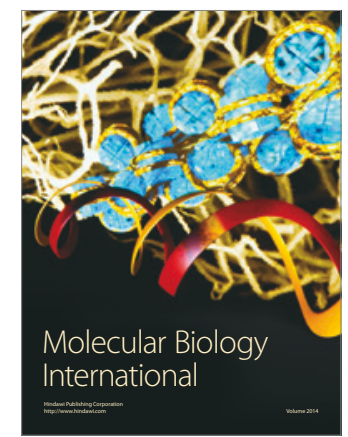

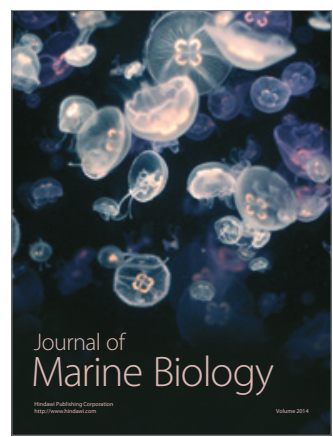

